\title{
Women's Inheritance Rights Reform and the Preference for Sons in India*
}

\author{
Sonia Bhalotra (University of Essex) \\ Rachel Brulé (NYU Abu Dhabi) \\ Sanchari Roy (King's College London)
}

13 July 2018

Accepted, Journal of Development Economics

\begin{abstract}
We investigate whether legislation of equal inheritance rights for women modifies the historic preference for sons in India, and find that it exacerbates it. Children born after the reform in families with a firstborn daughter are 3.8-4.3 percentage points less likely to be girls, indicating that the reform encouraged female foeticide. We also find that the reform increased excess female infant mortality and son-biased fertility stopping. This suggests that the inheritance reform raised the costs of having daughters, consistent with which we document an increase in stated son preference in fertility post-reform. We conclude that this is a case where legal reform was frustrated by persistence of cultural norms. We provide some suggestive evidence of slowly changing patrilocality norms.
\end{abstract}

JEL Classification: O12, K11, I21

Keywords: Inheritance rights, ultrasound, female foeticide, sex-selection, son preference, gender, India

\footnotetext{
* We thank the editor, Andrew Foster, and an anonymous referee for detailed and helpful comments. This paper was presented at a conference on Early Childhood Development in India September 15-16, 2017, sponsored by the Center for the Advanced Study of India (CASI) at the University of Pennsylvania as part of its $25^{\text {th }}$ year celebration and organized by Jere Behrman, Michel Guillot, Devesh Kapur (CASI Director) and Prakarsh Singh. We are grateful to Farzana Afridi, Jere Behrman and Prakarsh Singh for their detailed feedback and suggestions, and to the conference participants for helpful discussions. We would also like to thank seminar participants at the Barcelona Summer Forum 2018, CAGE-Warwick, CMPO-Bristol, King's Business School, Strathclyde Business School, Sussex, UNU-WIDER for their comments. Brule would like to thank Andrew Foster for kindly providing access to the REDS 2006 dataset. Bhalotra would like to acknowledge partial funding from ESRC Grant ES/L009153/1 awarded to the Research Centre for Micro-Social Change at ISER, University of Essex. Corresponding author: Sanchari Roy, Department of International Development, King's College London, London WC2B 4BG, United Kingdom. Email: sanchari.roy@kcl.ac.uk
} 


\section{Introduction}

Two centuries ago, women in Europe and America were considered the property of men (fathers or husbands), having no intrinsic rights of their own. Women's rights have been established by a long, slow process (described for instance in Doepke et al. 2012), in which legislation of their property rights was an important milestone. However, daughters still continue to have weaker property inheritance rights than sons in many developing countries today. In all of the Middle East and North Africa, in 50 percent of South Asian countries, 34 percent of sub-Saharan African countries, and 25 percent of East Asian and Pacific countries, inheritance laws either disfavour or altogether exclude women (World Bank 2011). Twenty-one of the 63 countries studied by Htun and Weldon (2011) have unequal property inheritance rights for men and women (WDR 2012).

This is potentially a major factor in compromising the position of women. Property, and in particular land, is a critical determinant of economic and social status (Agarwal, 1994). Property rights are associated with increased investment, productivity, access to credit and labour market opportunities (Besley 1995; Banerjee et al. 2002; Field 2007; Besley and Ghatak 2009; Ghatak and Roy 2007). Land markets in developing countries are scarce and land is typically acquired through inheritance. As a result, even amongst the landowning classes, women in developing countries continue to be asset-poor, and unequal inheritance rights tend to perpetuate the condition in which women find themselves reliant upon men, having limited earning capacity and limited options outside marriage (Field 2007; Goldstein and Udry 2008; Chung and Dasgupta 2007). The equalization of inheritance rights may therefore be expected to be a powerful instrument for the empowerment of women. This has potential impacts on women's labour supply (Joulfaian 2006), fertility (Ashraf et al. 2014), health (Jayaraman et al. 2013; Calvi et al. 2017) and mortality (Milazzo 2014). In addition, several studies show that the financial empowerment of women directly benefits children because women tend to invest more in children (e.g. Lundberg et al., 1997; Duflo and Udry 2004; Bobonis 2009; Baranov et al. 2017). There is also some evidence that women invest relatively more in girls, redressing gender inequality in the next generation (Thomas 1990, 1994; Dahl and Moretti 2008; Baranov et al. 2017).

However, causal evidence that property rights empower women is limited, and the available evidence is somewhat mixed. In the context of India, inheritance rights for women were equalized with the rights of men by five states that enacted legislative reforms between 1976 and 1994, with federal legislation imposing equal rights for all states in 2005. 
A handful of studies have exploited the staggered implementation of these reforms to examine impacts on different aspects of women's status in India. One study documents increased suicide rates among both men and women aged 15-44, with a significantly larger increase among men (Anderson and Genicot 2015). The authors rationalize this in terms of increased intra-household conflict, showing also an increase in domestic violence. Focusing on girls of school-going age, rather than on women who were of marriageable age or married at the time of the reform, Roy (2015) and Deininger et al. (2013) show that the reform was associated with increased educational investment in girls relative to boys. These results suggest that negotiating sharp changes in women's economic rights may increase marital conflict for some, while expanding marital prospects for others. ${ }^{1}$

In this paper, we ask a very different question. We investigate not whether equal property rights legislation empowers women within marriage or on the marriage market, but whether it modifies the historic tendency for Indian parents to prefer to have sons. There is hardly a more compelling statement of gender inequality in India than its unnaturally male-biased population sex ratio, an important driver of which is the desire to have sons. To what extent is this historic desire for sons driven by their stronger economic position and, in particular, their greater command over ancestral property? Might granting equal inheritance rights to daughters mellow the preference for having sons? Plausible mechanisms are that it would allow daughters to offer the old-age security that sons have traditionally provided to parents (Chung and Dasgupta 2007), or that it would diminish dowry, the burden of which raises the cost of having daughters (Anderson 2003, Bhalotra et al. 2016). These potential mechanisms are linked. Although dowry is now often appropriated by the groom or his parents, historically it was a pre-mortem bequest to daughters given at the time of marriage, while post-mortem bequests (typically of family property) went to sons (Goody 1973). This custom, evident in large parts of Europe and Asia, was premised upon married daughters leaving the parental home, in contrast to married sons who tended to co-reside with parents. Botticini and Siow (2003) model the institution of dowry jointly with patrilineal inheritance as emerging from parents' attempt to solve a free riding problem between siblings to create incentives for sons to provide

\footnotetext{
1 The increase in male relative to female suicides reported in Anderson and Genicot (2015) illustrates the difficulty with defining women's empowerment. It suggests that a challenge to the economic power of men generates greater distress or damage among men, but to the extent that the suicides are of married men, they create the perilous state of widowhood for women (Chen and Dreze 1992). However, their data are for all suicides among 15-44 year olds at the state-year level and not available by marital status. This may therefore represent suicides of unmarried men the bottom of the socioeconomic distribution who find it harder to match on the marriage market after the inheritance reform.
} 
effort. Therefore, legislation that compels parents to share post-mortem bequests equally with daughters may lead to erosion of dowry, and it may modify the convention of women marrying into households some distance away from their natal homes, while sons co-reside with or live close to parents (and family property). ${ }^{2}$ Thus, to the extent that dowry and coresidence with sons determine the preference for having sons, we may expect gender equality in property rights to lower son preference.

In this paper, we investigate this issue by modelling the sex ratio at birth as a function of whether the inheritance reform in the state of birth had been passed before the year of birth. To identify causal effects of equal inheritance rights for women, we leverage the staggered implementation of the inheritance reform across the Indian states, which created state and cohort-level variation in reform exposure, similar, for instance, to Miller (2008). We buttress this double difference using two further sources of variation that determine the degree of exposure to the reform. First, we interact the inheritance reform indicator with a cohort-varying indicator for availability of ultrasound technology. Previous work shows ultrasound availability generated a trend break in the sex ratio at birth (Bhalotra and Cochrane 2010). We exploit the fact that prior to the introduction of ultrasound technology that made prenatal detection of the sex of the foetus feasible, no significant manipulation of the sex ratio at birth is discernible in aggregate statistics (Bhalotra and Cochrane 2010). So, for the sex ratio at birth to have responded to the reform, the indicator for ultrasound access will need to have switched on. This aids identification because any omitted variables that drive a spurious relationship between the outcome variables and inheritance reform would have to have exhibited a discontinuous change that not only lines up with the particular state and year variation in reform (i.e. in the state of Kerala in 1976, in Andhra Pradesh in 1986 and so on) but, in addition, the omitted variables would have to have jumped in line with the date of introduction of ultrasound scans as well. Moreover, crossing the reform and ultrasound indicators helps us attribute any observed effects to parental manipulation of the sex ratio.

The final source of variation deployed towards identification is the sex of the firstborn child. Previous work shows that this is a) quasi-random and b) that it predicts

\footnotetext{
2 Patrilineality includes passing on the main productive assets through the male line, while women may be given some movable goods in the form of dowry or inheritance. This constrains women's ability to sustain their economic level of welfare without being attached to a man. Patrilocality involves a couple residing at the man's home, which goes hand in hand with inheritance, especially in peasant societies where land is the main productive asset that is inherited. Indeed, Agarwal (personal communication with Bhalotra) posits that persistence in kinship systems and marriage practices (among which the distance of post-marital residence from the natal home is particularly significant) "may help to explain the failure to realise in practice the significantly greater inheritance rights in landed property which South Asian women now enjoy as a result of recent legislative changes."
} 
sex-selective abortion in favour of male children: parents who, by the random hand of nature, are assigned a son at first birth are significantly less likely to engage in female foeticide for subsequent conceptions (see Almond et al. forthcoming, Almond and Edlund 2008, Abrevaya 2009, Bhalotra and Cochrane 2010, Anukriti et al. 2016). ${ }^{3}$ We also show that families with firstborn sons and families with firstborn daughters are balanced on all relevant observable characteristics.

To summarize, the treated group is defined as a cohort born post-reform and postultrasound in a family with a firstborn daughter. The control group includes families with firstborn sons and children born pre-reform or pre-ultrasound. We corroborate our findings of changes in sex-selective abortion behaviour using data on reported son preference (i.e. desired share of sons among births). We conclude with an attempt to investigate whether passage of the reform was associated with changes in patriarchal norms, in particular, whether daughters married closer to the natal home, and whether adult sons changed their propensity to co-reside with parents.

We use the three available rounds of nationally representative individual level data from the National Family and Health Survey (NFHS) pertaining to births between 1972 and 2004. We find a significant decrease of 3.8-4.3 percentage points in the probability that a girl is born post-reform and post-ultrasound in households where the firstborn child is a girl rather than a boy. This magnitude of decline is outside the biologically normal range. ${ }^{4}$ In Section 5.1, we put it in perspective, comparing with other studies and with rates of ultrasound scan use.

Our finding that female foeticide increased in response to inheritance reform is robust to the inclusion of state-year of birth fixed effects. These mop up variation in statelevel pro-female legislation that may have coincided with inheritance reform, for instance the establishment of Women's Commissions (discussed in Andersen and Genicot 2015). This is a relevant concern given that India has a federal system and a number of states have, at different times, implemented laws designed to limit the extent of sex-selective abortion (Sekhar 2012). State-year fixed effects also absorb the effects of economic influences on the desire for sons such as the increase in returns to education for girls relative to boys, as well as account for any differential state-level pre-trends in the outcome. Our results are also robust to controlling for mother's age and mother fixed

\footnotetext{
3 The premise that the sex of the first birth is random is also discussed and investigated in Bhalotra and Cochrane (2010) and Anukriti et al. (2016), using the same data as ours.

${ }^{4}$ For a discussion of the biologically normal range of the probability that a birth is a girl rather than a boy, and evidence of the size of deviations from this norm that were apparent immediately upon the introduction of ultrasound technology in India, see Bhalotra and Cochrane (2010).
} 
effects, which absorb all mother-specific time-invariant variables including unobservables such as her preference for sons or her fertility preferences (as well as, of course, observables such as her education, caste and religion). The mother's preferences may determine compliance and thus including mother fixed effects will adjust for any changes in the composition of women giving birth post-reform. In addition, our results are also robust to using an alternative dataset (REDS 2006). Additional robustness checks are discussed in Section 5.2.

The most plausible interpretation of our finding is that in the presence of sticky social norms, awarding inheritance rights to women makes parents more averse to having a daughter rather than a son. ${ }^{5}$ In line with this, we also find an intensification of stated preferences for sons relative to daughters after the reform of approximately 1 percentage point following the reform, compared to a sample mean of 0.57. Our findings are consistent with the theoretical framework of Botticini and Siow (2003). ${ }^{6}$

In research conducted in parallel with ours, Rosenblum (2015) shows an increase in excess girl mortality (after birth) following the inheritance reform. ${ }^{7}$ We focus on female foeticide as it is a particularly clean indicator of parental preferences for boys over girls - it involves an explicit decision to conduct prenatal detection of the sex of the child, and this needs to be followed up by the deliberate act of aborting the foetus if it is a girl. However, we also extend our analysis to study impacts of the reform on excess infant mortality among girls, and on son-biased fertility stopping. We find that the reform exacerbates son preference on both these margins. ${ }^{8}$ In particular, girls born post-reform and postultrasound in families with a firstborn girl are 2.3-3.2 percentage points more likely to die before their reaching first birthday (equivalent to $32-42 \%$ of the sample mean), relative to

\footnotetext{
${ }^{5}$ Patriarchal norms, including those that stipulate that adult sons co-reside with (elderly) parents, exert effort on the family farm or enterprise, and provide support, are slow to change. For instance, parents may be concerned that even if daughters did acquire property and thus the means to provide old-age support to their parents, their husband's family may appropriate the property or limit the daughters' capacity to provide care to their parents. Please see Section 2.a for further discussion.

${ }^{6}$ In their model, Botticini and Siow argue that male-biased inheritance emerges from parents' optimizing choices. Forcing parents to share post-mortem bequests between sons and daughters in patrilocal societies, where married daughters leave their parental home and sons do not, will tend to result in lower parental welfare. Hence it follows that equalizing inheritance rights creates incentives for parents to prefer not to have daughters.

${ }^{7}$ Estimates of the impact of the reform on child mortality are likely to be biased by sex-selective abortion, but the bias is downward implying that Rosenblum's conclusions are robust to this selection. The bias arises because child mortality is defined on a selected sample of conceptions that survive the foetal period to the point of birth. There is no similar bias in looking at changes in (sex-selective) survival of the foetus as done in our paper.

8 All estimates are intent-to-treat estimates. Different types of families may be at the different margins.
} 
boys. Moreover, children in families with firstborn girl are approximately 9 percentage points more likely to have a younger sibling (equivalent to $12 \%$ of the sample mean), relative to families with firstborn boy. Together with our sex ratio results, these findings provide compelling evidence in favour of our contention that the inheritance reform intensified son preference in fertility.

A natural question at this point is: if what we capture is a sticky social norm, do we find any corroborating evidence in support of this claim? In order to examine changes in patrilocal norms in response to the reform, we investigate co-residence of parents and adult sons and the distance of married daughters' homes from their natal home using a different dataset: the Rural Economic and Demographic Survey (REDS) 2006. We estimate an increase of 3 percentage points in the probability that a married daughter lives nearer the natal home (up to $10 \mathrm{~km}$ away), but this is not statistically significant. We also find no significant impact on the extent of co-residence with sons. Together, these results suggest that patriarchal norms change only very slowly if at all, so that a sharp legislative change intended to favour daughters appears to have raised the perceived cost of daughters enough that parents became more averse to having them. ${ }^{9}$

This paper provides the first evidence of the impact of the gender-equalizing inheritance reforms in Indian on female foeticide and son-biased fertility stopping behaviour. We also contribute to the literature by using a more stringent estimation strategy (permitting the use of state-year fixed effects as well as mother fixed effects) compared to existing studies analysing the impact of these reforms on various other outcomes. ${ }^{10}$ Our findings also contribute to existing evidence indicating that slow-moving social norms may frustrate the intentions of legal reform in the first decades after the passage of legislation (Aldashev et al. 2011).

The remainder of the paper is organized as follows. Section 2 describes the institutional background of the Hindu inheritance law in India, as well as details on the advent of ultrasound technology in the country. Section 3 describes the identification strategy and while Section 4 outlines the data and descriptive statistics. Section 5 presents the key results while Section 6 concludes.

\footnotetext{
9 Legislative change pertaining to the division of bequests is (in principle if not in compliance terms) immediate. In contrast, the linked institutions of dowry, patrilocality and co-residence with sons are expected to wither gradually, as a function of changes in the agrarian economy (Rosenzweig and Wolpin 1985, Guner 1998, Botticini and Siow 2003). In particular, we may expect that, as the returns to human capital rise, sons (and daughters) will acquire an education, and sons will no longer be tied to the occupations or assets of their fathers. This will spontaneously but gradually reduce co-residence and the attachment of sons' labour to ancestral property.

${ }_{10}$ Results of some of the previous studies are potentially vulnerable to bias from omitted state- and year-varying variables.
} 


\section{Background}

\section{2a. Inheritance Rights in India}

Gender inequality in inheritance rights in India was entrenched in The Hindu Succession Act (HSA) of 1956. Promulgated not long after India gained Independence from British rule, the HSA conferred the legal right to inherit ancestral property upon sons to the exclusion of daughters. Ancestral or "joint family property" consists of property principally inherited by an individual from their father, paternal grandfather or paternal greatgrandfather, plus any property that was jointly acquired by them or acquired separately but merged into the joint property. Separate property, on the other hand, includes that which was self-acquired (if acquired without detriment to the ancestral estate) and any property inherited from persons other than the individual's father, paternal grandfather or paternal great-grandfather (Agarwal 1994). Under the HSA, daughters of a Hindu male dying intestate (i.e. without a will) ${ }^{11}$ had equal inheritance rights as sons to only their father's separate property and his "notional" portion of joint family property, but had no direct inheritance rights to joint family property itself. Sons, on the other hand, not only inherited their share of the father's own property and his "notional" portion of joint family property, but also had a direct right by birth to a share of the joint family property. In fact, all persons who acquired interest in the joint family property by birth were said to belong to the "Hindu coparcenary", which is conceptually similar to an exclusive male membership club in relation to the issue of inheritance to which women had no access.

For millions living in rural India, the most common form of property is land that is typically family-owned, which makes the gender bias in inheritance rights quite a significant phenomenon. Note that, as the reform refers to ancestral property, households residing in urban areas may own ancestral property/land in villages or towns, and thus also be affected by the reform. Thus the HSA, by excluding the daughter from participating in the coparcenary ownership of ancestral property, discriminated against the daughter. This inequality is, arguably, fundamental to the vulnerability of Indian women (Agarwal 1994), who are passed from father to husband, their economic insecurity contributing to early

\footnotetext{
${ }^{11}$ According to Deininger et al. (2013), the proportion of people who die without making a will in India is very high (around 65\%, and probably even higher in rural areas). Recent newspaper articles have put the number at a much higher $80 \%$ (see https://timesofindia.indiatimes.com/Avoiddisputes-write-a-Will/articleshow/802650.cms and http://www. fpgindia.org/2011/07/writing-awill-know-some-facts.html). The main reason cited for such low prevalence of wills in India is that people often find it uncomfortable discussing a will in their lifetime because of the air of fatality and gloom that surrounds it. Thus, all this would suggest that the HSA 1956 is what ultimately determines inheritance patterns within the family.
} 
marriage, high fertility and domestic violence.

Inheritance is one of the topics in the Indian constitution over which both the federal and the state governments have legislative authority. In 1976, the state of Kerala amended the HSA, subsequently followed by the states of Andhra Pradesh in 1986, Tamil Nadu in 1989, and Maharashtra and Karnataka in 1994 (see Figure 1). These amendments granted women equal inheritance rights to ancestral property provided they were unmarried at the time of the reform. ${ }^{12}$ In 2005, the federal Government of India swept all remaining states into the fold in a momentous constitutional reform. ${ }^{13}$ Further discussion of the institutional details of the reform is in Roy (2015), Brule (2017), Andersen and Genicot (2015) and Rosenblum (2015).

As pointed out by Andersen and Genicot (2015), a key point to note here is that there does not appear to be any systematic reason for the specific years in which the different states amended the HSA. Nonetheless, our empirical estimations include state fixed effects, year fixed effects and state-year fixed effects. The last soak up variation in any other state-level pro-female legislation that may have coincided with inheritance reform, for instance the establishment of Women's Commissions (as discussed in Andersen and Genicot 2015), or other state-specific time-varying confounding factors.

Previous work has shown that the HSA amendments have been largely unsuccessful in improving inheritance of women (Roy 2015; Brulé 2017; Landesa 2013): the proportion of women inheriting property from their parents remains woefully small and, importantly, did not increase significantly following the reform. Parents may have been reluctant to give daughters any property due to patrilocality ${ }^{14}$ and the related risk that the property ends up being controlled by the in-laws of the daughters. It would thus be fair to ask why we may expect any impact of inheritance reform on parental manipulation of the sex composition of their children. In fact, the documented impacts in the cited studies refer to girls born before the reform. However, it is conceivable that, for the next generation of girls (the offspring of these women, who constitute the births in our study), the margin of adjustment is different.

\footnotetext{
12 Kerala passed a slightly different amendment in the form of the Kerala Joint Hindu Family System (Abolition) Act that recognized all family members with an interest in the undivided family estate as being independent full owners of their shares from then onwards, i.e. abolished joint family property altogether. But since the spirit of this amendment was similar to those passed by the other reforming states, and could be expected to favorably affect the inheritance of the daughter, we club them together.

${ }_{13}$ We focus only on the state-level amendments to the HSA in this paper, and hence restrict our data to 2004

${ }_{14}$ Patrilocality (also known as virilocality) is the social custom that requires married women to leave their parents' home and reside with their husband's family post marriage.
} 
A large literature provides evidence that Indian parents have, for centuries, manipulated the sex composition of their children through son-biased fertility stopping and through lower investments in daughters (see a brief survey in Bhalotra et al. 2016 for instance). Since the mid-1980s, the availability of affordable prenatal sex detection techniques (alongside pre-existing availability of abortion) has provided a new tool to meet this end (discussed in Section 2.b). If sticky patriarchal norms lead parents to still prefer to leave their property to sons, the perceived cost of having a daughter is higher after the inheritance reform. Either daughters inherit property alongside their brothers, and parents are potentially less protected in their old age, or parents circumvent the law and daughters stand to contest their disinheritance in court. Even if parents can circumvent the law and the probability that daughters contest is small, the risk could deter parents from having daughters because under risk-aversion, uncertainty is more heavily weighted for negative outcomes. In addition, parents may incur psychic costs associated with non-compliance with the law, and with alienating their daughters. In fact, the risk that daughters contest their rights is rising and parents can probably see this insofar as a number of NGOs (e.g. Marg, SEWA, and Bitiya and ActionAid's \#Property for Her campaign) now pro-actively encourage women to claim their rights and provide legal support. ${ }^{15}$ Also, the returns to contesting rights to property (land) are increasing in line with the trend of rising land prices across India. ${ }^{16}$ A recent study of 9,300 litigants across 170 district courts, balanced across civil and criminal cases, found up to two thirds of cases relate to land and property and more than half of these disputes occurred within families. ${ }^{17}$ As of September 2017, the Business Standard notes "land conflicts [are] brewing across the country," 18 as well as creating family feuds across national boundaries, ${ }^{19}$ echoing writing over the past decades on "growing conflict about land.",20

\footnotetext{
${ }^{15}$ See a summary of NGO initiatives on the UN Women's website here http://www.endvawnow.org/en/articles/943-provide-rights-based-education-and-awareness.html ${ }^{16}$ Rising agricultural land prices have been a noticeable trend across India since the early 2000s. As of 2013, M. Rajshekar reports a "3 to 100-fold rise in farm land prices" drawn from microstudies and anecdotal information on 68 villages in seven states gathered by the Economic Times: https://economictimes.indiatimes.com/news/economy/agriculture/great-rural-land-rush-3-to100 -fold-rise-in-farm-land-prices-may-not-bode-well/articleshow $/ 25607513 . \mathrm{cms}$

${ }_{17}$ Source: http://www.livemint.com/Politics/DIsifcuswHskm1jkXNdI2M/A-case-to-revisitIndias-land-laws.html

${ }_{18}$ Source: http://www.business-standard.com/article/economy-policy/conflicts-across-india-asstates-create-land-banks-for-industry-investment-117091900140 1.html

19 Source: http://www.bbc.com/news/world-asia-21171262

${ }^{20}$ Source: https://www.voanews.com/a/india-witnesses-growing-conflict-over-land101293609/124357.html
} 


\section{2b. Sex Ratios and Ultrasound Technology in India}

The phenomenon of "missing women" was initially highlighted in Miller (1981) and Sen (1990). Recent estimates suggest that among the stock of women who could potentially be alive in India today, over 25 million are "missing" (Anderson and Ray 2012). The population sex ratio in India has been unnaturally skewed in favour of males since the first recorded census. Historically, parents have manipulated the ratio of surviving girls to boys by the practice of son-biased fertility stopping (Arnold et al. 1998; Bhalotra and van Soest 2008) and multiple forms of neglect including breastfeeding duration, immunization and nutrition (Jayachandran and Kuziemko 2011; Oster 2009).

Since the availability of prenatal sex detection technology, it has become possible to manipulate the sex ratio by committing sex-selective abortion or female foeticide, the material and psychic costs of which tend to be lower than the costs of eliminating girls after birth. Abortion has been legal in India since 1972 and the costs of scans and abortion are affordable, albeit with prices increasing in the reliability and safety of these procedures. It is estimated that as many as 0.48 million girls or $6 \%$ of potential female births during 1995-2005 were selectively aborted annually during 1995-2005, which is more than the number of girls born in the UK each year (Bhalotra and Cochrane 2010). In contrast to the more subtle and uncertain procedure of neglect, foeticide is a conscious and staged act and, for this reason, it provides a clean measure of parents' preferences for having sons rather than daughters.

The first imports of ultrasound scanners are recorded in the mid-1980s, associated with India's first attempt at import liberalization (see Figure 2b). There was a sharp increase in availability in the mid-1990s, created by the relaxation of industrial licensing requirements, which led to domestic production of ultrasound machines. ${ }^{21}$ Bhalotra and Cochrane (2010) show that the sex ratio at birth for birth orders two and higher tracks the availability of ultrasound, and that a disproportionate share of foeticide is conducted in families with a firstborn girl. They also show that the sex of the firstborn child is quasirandom (see Figure 4 Panel A replicated from them) and Abrevaya (2009) shows this is also the case for Indian and Chinese families in US. Although stated son preference in India is declining over the sample period (Figure 3), Figure 4 Panel B shows a sharp drop in the probability of a female birth that appears after ultrasound is introduced and that this is evident only in families with a firstborn girl.

\footnotetext{
${ }^{21}$ For further details on the timing of availability of ultrasound technology etc. please refer to pages 12-13 in Section 5 of Bhalotra and Cochrane (2010).
} 
A common pattern in India and other patrilineal societies is that daughters take their bequest at marriage as dowry and marry some distance from their natal home (Guner 1998; Rosenzweig and Wolpin 1985), while sons tend to co-reside with parents, work on the land, and subsequently inherit it. Indeed, Botticini and Siow (2003) postulate that a rationale for the origin and persistence of these arrangements is that they incentivize sons to work on the father's land, contributing to wealth creation as well as old-age security.

\section{Identification Strategy}

Our objective is to obtain causal impacts of the inheritance reform on the preference for sons in India. For reasons discussed earlier, we focus upon son preference expressed in the stark act of sex-selective abortion (or female foeticide). With appropriate caveats, we seek to corroborate this with data on reported son preference. We then extend the analysis to study the impacts of the reform on excess girl mortality after birth, and son-biased fertility stopping, both of which are alternative ways of adjusting the sex composition of surviving births. This allows us to check whether prenatal mortality (foeticide) is simply substituting for postnatal mortality or fertility stopping behaviour, or if, potentially, different women respond to the reform on these different margins. ${ }^{22}$

The reform was implemented by individual state governments, so its incidence was staggered across the states, generating potential discontinuities in the outcome specific to state and birth year. However, as sex-selective abortion was infeasible prior to availability of prenatal sex detection technologies (which we henceforth abbreviate as "ultrasound"), we expect that any impacts of the reform on desired sex ratios will only be evident in the actual sex ratio at birth among post-ultrasound cohorts. We therefore interact an indicator for cohorts born post-reform $\left(R_{s}\right)$ with an indicator for cohorts born post-ultrasound $\left(\right.$ Post $t_{t}$, allowing for the main effects of each.

The initial estimated equation for sex ratios is:

$$
y_{\text {imst }}=\alpha_{s}+\beta_{t}+\delta R_{s t}+\theta\left(R_{s t} * \text { Post }_{t}\right)+\varepsilon_{\text {imst }}
$$

where $y_{\text {imst }}$ is a binary variable that equals 1 if child $i$ born to mother $m$ in state $s$ in year $t$ is a girl and zero otherwise, multiplied by 100 so that the regression coefficients can be interpreted as percentage point changes in the sex ratio at birth. $\alpha_{s}$ and $\beta_{t}$ represent state and year of birth fixed effects. $R_{s t}$ is a dummy variable that equals 1 for cohorts born after

${ }^{22}$ We do not directly analyse investments after birth because data on investments (including breastfeeding, vaccinations, visits to the doctor etc.) are only gathered for children born 3-5 years before the survey date. The survey dates of the NFHS rounds are such that we do not have sufficient pre- versus post-reform variation in these data. However, other studies show that underinvestment in girls (relative to boys) maps into excess girl mortality in India (see Anukriti et al. 2016, and references therein). 
the reform in a reforming state and zero for cohorts born before the reform or in a nonreforming state. For instance, $R_{s t}$ defines potential births in Kerala in 1972-1975 and in Karnataka in 1972-1993 as unexposed to the reform, and potential births in Kerala in 1976-2005 and in Karnataka in 1994-2005 as exposed.

In the absence of sex-selection, the outcome probability (i.e. the probability that a birth is a girl) is close to a half (see Appendix Table A2c). After and only after the introduction of ultrasound scanners, the share of girls at second and higher-order births has declined steadily, and the magnitude of the decline lies outside the range regarded as consistent with biological variation or slow-changing environmental factors (Bhalotra and Cochrane 2010). Following Bhalotra and Cochrane (2010) who test and defend this formulation with reference to the timing of the first ultrasound scanner imports in India, we construct a dummy variable Post $_{t}$ which equals 1 if the year of the child's birth is after 1985 and zero otherwise. Since diffusion of ultrasound scanners at the state level is likely to be correlated with demand, we use the national timing of ultrasound availability determined by exogenous changes in India's import tariffs. The coefficient of interest in this specification is $\theta$, which captures the differential impact of the inheritance reform on sex ratios at birth after the availability of ultrasound technology.

A familiar concern with difference-in-difference specifications such as (1) is that there may be state-specific time-varying omitted variables that are correlated with the introduction of the inheritance reform. Put differently, the identifying assumption is that the dates of introduction of the reform are not correlated with pre-trends in the sex ratio at birth.

We create within-state variation in the incentive to sex-select at the family level by the sex of the firstborn child on the premise that this is quasi-random: parents who, by the random hand of nature, are assigned a son at first birth are significantly less likely to engage in female foeticide for subsequent conceptions. This is supported by our data. Firstly, Panel A of Figure 4 shows that the proportion of females among first births in India lies within the normal range (48.8-49.26 percent) during our sample period, and shows no tendency to change over time. Secondly, Table 8 shows that families with firstborn boys and those with firstborn girls are similar along a number of observables. ${ }^{23}$ Thirdly, we find no significant change in sex ratio of first births post reform post ultrasound (see Appendix Table A2c). Finally, exogeneity of firstborn sex has also been previously defended in other

\footnotetext{
${ }^{23}$ Appendix Table A14 shows that this holds for both pre-reform and post-reform periods in our NFHS sample.
} 
studies (Almond and Edlund 2008; Abrevaya 2009; Dasgupta and Bhat 1997; Bhalotra and Cochrane 2010).

Using the randomness of sex of firstborn child begets us two advantages. First, any omitted variables at the state-year level would now have to vary systematically between families in a state and birth-year with the sex of the firstborn child. Second, we can now include state-year fixed effects that flexibly control for any omitted state-year variation that may be correlated with the passage of inheritance reform. This richer, more rigorous specification is:

$$
\begin{gathered}
y_{\text {imst }}=\alpha_{s}+\beta_{t}+\gamma_{s t}+\delta R_{s t}+\theta_{1} \text { firstgirl }_{m}+\theta_{2} \text { firstgirl }_{m} * R_{s t}+\theta_{3} R_{s t} * \\
\text { Post } \left._{t}+\theta_{4} \text { firstgirl }_{m} * \text { Post }_{t}+\theta_{5} \text { (firstgirl }_{m} * R_{s t} * \text { Post }_{t}\right)+\varepsilon_{\text {imst }}
\end{gathered}
$$

where firstgirl $_{m}$ is an indicator for the firstborn child of the mother $m$ being female, $\gamma_{s t}$ denotes state-year fixed effects, and the rest of the notation are as defined for equation (1). We consistently control for all of the underlying main effects and secondary interaction terms. ${ }^{24}$ Since we include state-year fixed effects, the level effect of the reform $(\delta)$ and the coefficient $\left(\theta_{3}\right)$ on the interaction term $R_{s t} *$ Post $_{t}$ are no longer identified. However, our confidence that we identify causal effects is substantially increased. The coefficient of interest is now $\theta_{5}$, which captures the impact of inheritance reform on the relative chances that a birth is female in households with a firstborn daughter relative to households with a firstborn son in the post-ultrasound period. We model the sex ratio only for second-order births to mitigate concerns about potentially endogenous continuation of fertility. However, the pattern of our results remains broadly similar when we include third and fourth-order births, although the coefficients are smaller and not consistently statistically significant across all specifications (see discussion in Section 5.2).

As discussed in Section 2.b, although ultrasound scanners were imported into India from the mid-1980s onwards, there was a sharp increase in their supply once local production was initiated in the wake of industrial de-licensing and related economic reforms in the mid-1990s (Figure 2a). ${ }^{25}$ To capture this non-linearity in evolution of supply,

\footnotetext{
${ }^{24}$ In other words, we control for the main effect "firstgirl", an indicator for families with a firstborn girl vs a firstborn boy. As having a son confers "status" on Indian women, it may be that mothers with firstborn boys have more say and are allowed to keep a later-born girl. This is accounted for by the main effect.

${ }^{25}$ The first private clinic offering sex determination is thought to have appeared in 1982-83 (Sudha and Rajan 1999). After that supply increased at an increasing rate, fuelled by imports and the growth of local production. In the mid-1990s large-scale local production of ultrasound scanners was initiated by General Electric and other multinational firms in joint ventures with Indian firms (Grover and Vijayvergiya 2006, Mahal et al. 2006, Murthy et al. 2006). Government data show that the number of ultrasound machines manufactured in India increased 15-fold between 1988 and
} 
we divide the post ultrasound period into an early and a late diffusion period and replace Post $_{t}$ with $p_{2}$ and $p_{3}$ in Equations (1) and (2), where $p_{2}$ equals 1 for 1985-94 (early ultrasound period) and $p_{3}$ equals 1 for 1995-2004 (late ultrasound period). $p_{1}$ is the omitted category that captures the pre-ultrasound period 1972-1984. The rationale for these choices is detailed in Bhalotra and Cochrane (2010). Our findings are not sensitive to varying the cut-off years by one or two years on each side of the chosen thresholds or to using Post $_{t}$ instead of $p_{2}$ and $p_{3}$ separately (results are available on request).

Since the reform is at the state level and the sex of the firstborn child is quasirandom, any differential uptake of ultrasound scans and sex-selective abortion facilities across mothers within a state will affect interpretation of the distribution of impacts on the treated but will not bias interpretation of the average intent-to-treat effects. However, there may be mother-level selection into conception that is correlated with the inheritance reform and the availability of prenatal sex detection facilities. To allow for this, we show estimates conditional upon mother fixed effects. These comprehensively control for timeinvariant differences between mothers in preferences, information and local facilities. The estimated equation looks similar to (2) except that $\alpha_{s}$ is replaced with $\alpha_{m}$.

As discussed earlier, previous studies on India's inheritance reform exploit state and birth cohort variation in exposure to reform, which leaves the estimates vulnerable to bias from omitted state- and year-varying variables. In addition, previous studies either impose an age of exposure of the mother (e.g. Roy 2015) or use aggregate data and thus cannot account for individual variation in exposure (e.g. Anderson and Genicot 2015). In contrast, our paper has a clean measure of exposure defined on the potential birth year of the child, obtains within-mother estimates, as well as shows robustness to using motherlevel exposure to the reform (see Section 5.1). Our identification strategy is therefore considerably more stringent.

The specification that we estimate to investigate changes in reported son preference is the same as Equation (2), with the dependent variable being the desired or ideal number of sons divided by the desired or ideal number of total children, as reported by the mother. The resulting variable is bounded between 0 and 1 . However, this is measured only at the time of survey. We construct a time-varying measure of reported son

2003 with especially marked increases after 1994 (Grover and Vijayvergiya 2006, Murthy et al. 2006, George 2006). Ultrasound scans dominate prenatal sex-determination, as they are relatively cheap and non-invasive. The technology is continuously improving, providing finer resolution of the fetal image earlier in pregnancy, and the scanners are growing smaller and more mobile. 
preference based upon the age of the mother at the time of the survey by exploiting cohort variation in stated preferences. We assume that son preference at age 20 determines fertility choices, but we confirmed that small variations on this choice of age made no significant difference to the results. ${ }^{26}$ Thus, women aged 20 in the survey year 1998 will define son preference for their cohort for the year 1998, while the preferences of women aged 40 who were surveyed in 1998 will define son preference in 1978, the year in which they were age 20. This assumes that reported preferences do not vary within woman as a function of her ages or her fertility experience. This is a strong assumption and so we only regard these findings as auxiliary - as an attempt to look at whether stated preferences are consistent with our evidence on behavioural change. In this specification, the "Reform" variable $R_{s t}$ is a dummy variable that equals 1 if the mother is 20 years old at the time of the reform in the reforming state and zero otherwise.

We also estimate the impacts of the inheritance reform on excess girl mortality and fertility, using the specification of Equation (2). In case of mortality, the dependent variable captures whether or not the child died on or before reaching their first birthday, multiplied by 100 . We present results differentially by gender of child. In case of fertility, the dependent variable is an indicator for whether or not the child has younger siblings, multiplied by 100 .

\section{Data and Descriptive Statistics}

We primarily use the National Family Health Survey (NFHS) which records the complete fertility histories of women aged 15-49 and thus allows us to identify the sex and birth year of every child for a representative and large sample of women. The birth histories of women span the pre- and post-reform periods in every reforming state. In addition, the birth histories identify biological children of a mother rather than all children in a household. The surveys also ask women their desired number of children, and the desired numbers of sons and daughters. The NFHS is a household survey representative at the state level, covering 26 states of India, ${ }^{27}$ and it was conducted in three waves in 1991/2, 1998/9 and 2005/6. We pool the three rounds and use data on birth cohorts 1972 to 2004. As mentioned in Section 3, we restrict the sample for our main analyses to up to secondorder births (but also present additional results later including up to third and fourth-order

$2670 \%$ of women in our NFHS sample have had their first child by the age 20 . The median age at first birth is 18 . Our results for son preference are robust to using 18 instead of 20 years as the cutoff age for mother's son preference to determine her fertility choices.

27 The HSA (1956) did not apply to Jammu and Kashmir (Agarwal, 1995), hence this state is excluded from the analysis. In addition, Sikkim, one of the smaller states, is not part of the 1992 wave. 
births for robustness). The total number of births is 490,833 , born to 169,728 mothers. Of this, 169,728 are first order births and 136,013 are second order births.

Descriptive statistics are presented in Appendix Table A12. The mean sex ratio (females/males) is 0.48 while mean son preference (defined as the ratio of ideal number of sons over ideal number of total children reported by mother) is 0.57 . Appendix Table A13 shows a pre-reform balance test between reforming and non-reforming states. The only systematic difference is in reported son preference.

In order to explore the impact of the inheritance reform on co-residence of parents and sons and the distance of daughters' marital home from their natal home, we use the Rural Economic and Demographic Survey (REDS) 2006. The REDS is a nationally representative survey for rural India that covers 17 major states. ${ }^{28}$ To maintain comparability with the NFHS sample, we use data on birth cohorts 1972 to 2004. The analysis sample comprises 41,105 individual births born to 8,154 mothers. Of this, 6,498 are first order births and 5,941 are second order births.

\section{Results}

\subsection{Sex Ratios at Birth}

Table 1 presents estimates of Equation (2). The reported coefficients are the tripledifference coefficients that capture the differential impact of the reform on the probability that a birth is female among post-ultrasound cohorts in families with a firstborn girl relative to families with a firstborn boy. ${ }^{29}$ Our estimates in Column 1 indicate a significant decline in the probability that a birth is a girl by 3.8-4.3 percentage points. These results are robust to inclusion of household level control variables (Column 2), state-specific linear trends (Column 3) and state-year fixed effects (Column 4). Our estimates are larger though not statistically significantly different conditional on mother fixed effects (Column 5). All throughout, we cannot reject equality of the coefficients for the two periods marking early and late diffusion of ultrasound. This is plausible given that "treatability" was higher in the first period (low hanging fruit) while availability of ultrasound was higher in the second period, and these differences may offset one another.

\footnotetext{
${ }^{28}$ The 17 major states are: Punjab, Haryana, Uttar Pradesh, Rajasthan, Bihar, West Bengal, Madhya Pradesh, Gujarat, Maharashtra, Karnataka, Kerala, Tamil Nadu, Andhra Pradesh, Orissa, Chattisgarh, Uttarkhand and Jharkhand, which account for more than $92 \%$ of the total population of India (Census of India, 2011).

29 The full specification (including the double and triple-differences and level coefficients) is reported in Appendix Table A1.
} 
The estimated effect size is large. ${ }^{30}$ However, compared with recent papers in which the sex ratio is an outcome (some using the same Indian data), it does not seem implausible. Bhalotra, Chakravarty, Mookherjee and Pino (forthcoming) find that among Hindu families, above-median tenancy registration rates in West Bengal in eastern India raised the proportion of boys born at second and higher birth order by 5.2 percentage points, an effect that is larger than here. Bhalotra, Clots and Iyer (2018) find that "replacing" a Hindu with a Muslim state legislator increases the probability of a girl birth in the district from which they are elected by 1.8 percentage points. This is a large effect if one considers how little leeway a Muslim legislator might have to influence sex-selection among Hindus. In the current setting, it seems plausible that a legal reform that challenges deeply entrenched social norms has a larger impact. Almond et al. (forthcoming) find that, among second births that followed a firstborn girl, sex ratios increased by 2.8 percentage point in the four years following land reform in China. This is a smaller effect than here but it refers to a time (1978-1984) when the cost of accessing ultrasound access was still high in China and it was largely only available in provincial capitals. In contrast, our study covers a period through which ultrasound had diffused rapidly through India, reaching the Southern states and rural areas, and was available at low cost.

Since sex ratios have historically been less male-biased in the Southern states of India (Miller 1981, Sen 2003), there is a common perception that there are lower rates of sex-selective abortion in the South. Since the reforming states are in the South, we conducted a plausibility check by investigating reported ultrasound usage in the reforming states. Ultrasound scans are a necessary albeit not sufficient condition for prenatal sexdetection. ${ }^{31}$ The 1998 and 2005 rounds of the NFHS ask whether or not the mother had an ultrasound scan in the 3-4 years preceding the survey date. Using this we find that mean ultrasound usage in reforming states was $16 \%$ compared to $7 \%$ in non-reforming states, with the difference of 9 percentage points being statistically significant at the $1 \%$ level (Appendix Table B3). ${ }^{32}$ These are means over families with first born daughters and sons. Since sex-selective abortion is significantly higher in first-girl families (see Bhalotra and

\footnotetext{
${ }^{30}$ It is $61-69 \%$ of the potential female births that Bhalotra and Cochrane (2010) estimate did not occur in an all-India sample due to ultrasound use during 1995-2005.

${ }^{31}$ In other words, a scan may be conducted as prenatal check and not be followed by abortion but for purposive girl abortion to occur, information on foetal sex is a necessary pre-condition. Similarly, data on use of scans in an area indicates availability (supply), even if it also represents demand.

32 It is also striking that the penetration of ultrasound access in rural areas (which were more likely to have been affected by the inheritance reform as it referred to ancestral property, a lot of which is land) was significantly greater in the reforming than in the non-reforming states, at $10 \%$ vs $4 \%$ (see Appendix Table B4).
} 
Cochrane 2010), 16\% would be a lower bound since first-girl families are roughly half of all. In any case, the fact that this is larger than the estimated effect size in our analysis of about 4 percentage points enhances the plausibility of our results. Please see Online Appendix B.

We also investigated using the exposure of the mother to the reform (a function of her birth cohort) rather than exposure of her potential births (a function of the years in which she makes reproductive decisions). The estimating equation for this specification is:

$$
f_{m s t}=\alpha^{\prime}{ }_{s}+\beta^{\prime}{ }_{t}+\gamma^{\prime}{ }_{s} t+\delta^{\prime} E_{s t}+\varepsilon_{m s t}
$$

where $f_{m s t}$ denotes the proportion of female births to mother $m$ who was born in year $t$ living in state $s$. This is specifically measured as $G /(G+B)$ where $G$ is the number of girl children and $\mathrm{B}$ is the number of boy children born to the mother. The mother's exposure to the inheritance reform is denoted by a binary variable $E_{s t}$ that equals 1 if the mother was 14 years old or younger at the time of reform and zero otherwise. ${ }^{33}$ The coefficient of interest is $\delta^{\prime}$ which captures the differential impact of the reform on the proportion of female births to treated mothers, relative to control mothers (i.e. those who were 15 or older at the time of reform in the reforming states or those who lived in non-reforming states). The results are presented in Appendix Table A7. We estimate that the proportion of female births declined by 1 percentage point in response to the reform (Column 1), after controlling for state and mother's year of birth fixed effects. This is consistent with our increased female foeticide results for child-level exposure presented in Table 1, although the exact magnitudes of these coefficients are not directly comparable. ${ }^{34}$ The mother-level result is robust to controlling for household level variables (Column 2). With the inclusion of state-specific linear trends in Column 3, the magnitude of the coefficient remains unchanged even if it loses statistical significance at conventional levels.

\subsection{Sex Ratios at Birth: Robustness Checks}

We have already discussed robustness of our sex ratio results to some fairly demanding controls, including state-year fixed effects and mother fixed effects. We now present some further checks.

\footnotetext{
33 The state-level reforms that we investigate here only affected the inheritance potential of women if they were unmarried at the time of the passage of the reform in their state. Data from NFHS indicates that less than $10 \%$ women are married before turning 14 .

34 The dependent variable in the child-level exposure results on female foeticide is an indicator for a girl birth (multiplied by 100) and so the coefficients are percentage point changes in the chances of having a girl birth. Here, in case of the mother-level exposure results, the dependent variable is instead the share of girls among all children born to a mother.
} 
We control for state-year variation in the establishment of State Commissions for Women which, in principle, may confound the estimated impacts of the inheritance reform on sex ratios at birth. In fact, our inclusion of state-year fixed effects addresses this (and all other state-year varying omitted variables) but we nevertheless do this to identify how the coefficient of interest changes in response to controlling for this identified reform. ${ }^{35}$ First we include an additive control but in a second specification we interact the Women's Commission indicator with firstgirl ${ }^{*}$ post (see Table 2, Columns 1-2). In both cases, we control for state-specific linear trends instead of state-year fixed effects. Our results stand up to this specification change.

Maharashtra and Karnataka passed the reform after the constitutional amendment mandating a third of seats in village councils for women in local government in India. We test robustness of our results to the exclusion of Maharashtra and Karnataka from the sample (see Table 2, Column 3). The coefficients are not significantly different.

Since the reforming states are all in southern India we need to address the potential concern that we are merely picking up a "southern state effect". Although inclusion of state fixed effects and state-year fixed effects ought to account for any such time-invariant or time-varying effects, we nevertheless repeat our analysis by restricting our sample to only the reforming states i.e. Kerala, Andhra Pradesh, Tamil Nadu, Maharashtra and Karnataka, allowing us to exploit variation in dates of reform within southern Indian, rather than variation between the southern and the northern parts of the country. With this restricted sample, we are no longer able to identify different coefficients for the early and late diffusion of ultrasound because all the reforming states had passed the reform by 1994 . Hence, we use a common post period that covers the entire period of ultrasound availability from 1985 onwards. Due to the smaller number of clusters, we adjust standard errors using wild t-bootstrapping following Cameron, Gelbach and Miller (2008). We continue to find evidence for increase in female foeticide following the passage of inheritance reform (see Table 2, Column 4). Note that the southern states have historically exhibited lower son preference ${ }^{36}$ and are known to be more gender progressive than states in north India. Thus, it seems reasonable to think that these states would equalize

\footnotetext{
35 Anderson and Genicot (2015) control for legal changes such as this but their outcome (suicide) is measured at the state-year level, and so their specification cannot accommodate state-year fixed effects.

${ }^{36}$ Appendix Table A13 indicates that reported son preference in our NFHS dataset is 0.56 in the southern states compared to 0.6 in the rest of India.
} 
inheritance rights for women earlier. This is likely to be correct, but we address it in our analysis. ${ }^{37}$

Alternative explanations for sex ratios at birth becoming more male-biased in general include differential access to technology across families, differences in returns to education for boys versus girls, etc. However, our strategy effectively looks for systematic differences between first-son and first-daughter families that, we show, are balanced on observable characteristics (see Table 8). This implies that our findings are robust to these macro-level changes. Moreover, our strategy does not pick up general trends in the sex ratio but, rather, sharp changes in the sex ratio coincident with the introduction of inheritance reform.

Another concern may be that sex ratio at birth of second born children is unlikely to reflect the (complete) average effect of reform on a family's total gender composition of children as mother's fertility is unlikely to be complete. To address this concern, we test the robustness of our sex ratio results by restricting our sample to mothers who have completed fertility defined in one of two ways: a) mothers aged 35 or more at the time of survey and b) mothers whose actual fertility is greater than desired fertility. As Table 2, Columns 5-6 indicates, our results remain qualitatively unchanged.

As mentioned in Section 3, we focus upon second births to mitigate the concern that a select group of women progresses to third and higher birth orders, while $93.7 \%$ of Indian women have a $2^{\text {nd }}$ birth (NFHS data). However, we also test the robustness of the sex ratio results to including up to third births (see Appendix Table A2a) and up to fourth births (see Appendix Table A2b). The pattern of results is similar, indicating increased female foeticide after the reform, but the coefficients are smaller and not consistently statistically significant.

Since the inheritance reform was to the Hindu Succession Act and pertained to land, we may expect it to have had larger impacts on Hindu land-owning households than on Muslim or landless households. If we make no pre/post ultrasound distinction in the specification, we obtain the expected significantly larger impact of the reform among Hindu land-owning households (see Appendix Table A3). ${ }^{38}$ This is in line with previous

\footnotetext{
37 We do this essentially by controlling for state-year fixed effects and looking to identify sharp changes in the trend in the sex ratio at birth in firstborn girl families relative to firstborn boy families that are coincident with the state-specific year of the reform. We find increased female foeticide following the reform even though these are states with lower son preference.

38 The coefficient on firstgirl* reform *Hindu*land-owning is a bit smaller than the coefficients of interest in Table 1 because the latter isolates this effect post-ultrasound.
} 
studies (e.g. Rosenblum 2015; Roy 2015) that have looked at effects of the reform on other outcomes. ${ }^{39}$

The reason we did not leverage the greater exposure of Hindu land-owning households to the reform for our main specification is that our paper involves an interaction between inheritance reform (which changed incentives) and indicators for the availability of ultrasound scanners (which lowered costs). However, access to ultrasound did not line up with exposure to inheritance reform. In particular, Muslims and landless households were less affected by the reform but, on account of living disproportionately in urban areas, they had earlier/greater access to ultrasound facilities (see Online Appendix C).

We test the robustness of the sex ratio results to using the alternative dataset, REDS 2006 (see Appendix Table A4a). We observe a similar pattern of results as with NFHS. ${ }^{40}$ We also repeat the array of further robustness checks outlined above using REDS 2006 (see Appendix Tables A4b and A4c) and observe a similar pattern of results.

Given that the non-reforming states are diverse, we test whether our results are robust to excluding certain states from this control sample. The magnitudes of the coefficients of interest are robust to dropping first the northern and then the eastern states, although statistical significance is lost in the latter case (Appendix Tables A5 and A6). ${ }^{41}$

To recapitulate, we exploit variation in year of inheritance reform created by five states having reformed before a nationwide reform was implemented in 2005. As a coherence check on our findings, we looked to see whether was a decline in the share of female births in the late reforming states after 2005. We cannot obtain causal estimates of this but the data are consistent with it. According to the Census of India (2011), the sex ratio in the 0-6 year age group fell from 918 to 911 females per 1000 males for the major late reforming states (and for early reforming states, from 944 to 938).

Finally, Indian states are large regions that, in many cases, have their own languages and inter-state migration is small in general (Topalova 2010). However, we cannot rule out that the reform may have stimulated inter-state migration. Since we measure the incidence of reform in terms of the potential birth year of the child, a specification including mother fixed effects ensures that selective migration will not bias our estimates unless it occurs between births. To investigate this potential bias, we re-estimate the equation restricting

\footnotetext{
${ }^{39}$ Online Appendix D discusses some of the measurement issues with land ownership in NFHS as well as REDS.

${ }^{40}$ The coefficients are larger but the sample is now rural and not matched to the NFHS sample.

${ }^{41}$ The northern states are Haryana, HP, New Delhi, Punjab, Rajasthan and UP. The eastern states are Assam, Bihar, Arunachal Pradesh, Manipur, Meghalaya, Mizoram, Nagaland, Orissa, Sikkim, West Bengal and Tripura.
} 
the sample to women who had not migrated between births. This can be done because the NFHS surveys ask women how long they have lived in their current place of residence, and we know the birth year of their first and last child. Since the current place of residence is much more local than their state, this is a stringent test. Our results are robust to this (available on request).

\subsection{Reported Son Preference}

Table 3 reports results for stated son preference. The reported coefficients are the tripledifference coefficients. ${ }^{42}$ We find that families with firstborn girls are 1 percentage point more likely to report preferring sons over daughters relative to families with firstborn sons, post-reform and post-ultrasound (Column 1). This is robust to inclusion of household level controls (Column 2), state linear trends (Column 3) and state-year fixed effects (Column 4). ${ }^{43}$ These results are therefore consistent with evidence of sex selection discussed earlier. Women who are in the early reproductive years (around age 20) after the reform report higher son preference than women of the same age before the reform. This result is particularly striking since overall son preference has been declining in India (Figure 3). Thus reported preferences for sons move in line with revealed preferences for sons (revealed in manipulation of the sex ratio at birth and, as we shall see below, also in postbirth girl mortality and son-biased fertility stopping).

\subsection{Excess Girl Mortality After Birth}

Excess girl mortality after birth is an alternative to female foeticide when parents want to adjust the sex composition of surviving births. Our results for the impact of the reform on excess girl mortality are presented Table 4. The reported coefficients are the tripledifference coefficients. ${ }^{44}$ The estimates indicate that post-reform and post-ultrasound, girls in families with a firstborn girl are 2.3-3.2 percentage point more likely to die before reaching their first birthday, relative to boys (Column 1). This effect is equivalent to $32-$ $42 \%$ of the sample mean for child mortality among girls (which is $7.3 \%$ ). This result is robust to inclusion of all controls (Columns 2-5). In contrast, boys in families with a firstborn girl are 1.2-1.6 percentage point less likely to die before reaching their first birthday relative to the control group. Averaging across the country, there is evidence of some substitution of postnatal mortality with prenatal mortality (foeticide) in the post-

42 The full specification (including the double and triple-differences and level coefficients) is reported in Appendix Table A8.

${ }^{43}$ Since by construction, the dependent variable does not vary within mother, we do not present results from a specification with mother fixed effects for reported son preference.

${ }_{44}$ The full specification (including the double and triple-differences and level coefficients) is reported in Appendix Table A9. 
ultrasound period (Anukriti et al. 2016). Here we see that in the reforming states, the equalization of inheritance rights led to the elimination of girls in both ways, before and after birth. This is consistent with different women responding to the inheritance reform on these different margins.

\subsection{Son-Biased Fertility Stopping}

A further margin of adjustment in the sex of surviving births is son-biased fertility stopping. Our estimates for the impact of the reform on such behaviour are presented in Table 5. The reported coefficients are the triple-difference coefficients. ${ }^{45}$ We find that, following inheritance reform, in the late ultrasound period $\left(p_{3}\right)$, children in families with a firstborn girl are approximately 9 percentage point more likely to have a younger sibling (equivalent to $12 \%$ of the sample mean) relative to the control group (Column 1 ). The coefficient for the early ultrasound period $\left(p_{2}\right)$ is also positive, though not statistically significant. ${ }^{46}$ These results are robust to controls (Columns 2-4), and increase in magnitude following the addition of mother fixed effects (Column 5).

Taken together, our finding that inheritance reform exacerbates son preference in each of the three domains in which it may be potentially exercised, is compelling. As discussed in Section 5.3 above, this is also corroborated with available data on reported son preference. Given the caveats discussed earlier with the stated preference results, we underline the behavioural evidence of son-preferring behaviours in three different domains, all of which are consistent with stated son preferences.

\subsection{Investigating (Shifting) Social Norms}

Historically, sons have enjoyed inheritance rights to family property in the form of postmortem bequests in societies where daughters receive pre-mortem bequests in the form of dowry (Goody 1973). Botticini and Siow (2003) formalize this in terms of parents incentivizing sons to provide effort on family property. A critical premise is that sons stay and co-reside with parents while married daughters leave the parental home (patrilocality). Forcing parents to share post-mortem bequests equally between daughters and sons may therefore have implications for familial ties. In this section, we explore using REDS 2009 the impact of the inheritance reform on two specific dimensions of such ties: co-residence of parents and adult sons, and distance of daughters' marital homes from their parental homes.

45 The full specification (including the double and triple-differences and level coefficients) is reported in Appendix Table A10.

46 We cannot reject the equality of the coefficients for the two ultrasound periods at conventional levels. 
By requiring parents to give daughters and sons equal portions of ancestral property, the inheritance reform limits parents' ability to reward sons' effort invested in family property that may in turn lower their inclination to co-reside. Hence, we first test whether exposure to the reform impacts the incidence of co-residence between parents and adult sons. Co-residence is the most widespread form of physical, emotional, economic, and social security for parents in contemporary India. 56\% of families in our REDS sample co-reside with adult sons.

We define a parent-offspring pair in a given household as "exposed to reform" if there is at least one daughter in the household who is 14 years or younger at the time of reform (i.e. likely to be unmarried). ${ }^{47}$ This is similar to our measure of mother's exposure to reform (Equation 3). We study two sets of parent-offspring pairs: the household head's parents (i.e. grandparents) residence with the head and his or her siblings, and the household head's residence with his or her children. Adult sons are defined as married men aged eighteen years or older at the time of the survey. ${ }^{48}$ We restrict the sample to the subset of families with at least one living parent and one adult son, with any number of adult daughters (including none).

The estimating equation for co-residence of parents and adult sons is:

$$
C_{\text {ihgst }}=\alpha^{\prime \prime}{ }_{s}+\beta^{\prime \prime}{ }_{t}+\gamma^{\prime \prime} t_{s t}+\mu^{\prime \prime} E_{\text {hgst }}+\varepsilon_{\text {ihgst }}
$$

where the dependent variable of interest, $C_{\text {ingst }}$ is a dummy variable capturing whether or not any surviving parent $i$ (parent with adult children) in a given natal household $h$ from parent-child pair of generation $g$ in state $s$ born in year $t$ co-resides with an adult son. $E_{h g s t}$ is a dummy variable that captures the pair's exposure to reform as defined above.

The results are presented in Table 6. Conditioning on state and year of birth fixed effects and household level control variables, the coefficient on exposure to reform is negative but not statistically significant (Column 1). Restricting to married adult sons only, and adding either state linear trends or state-year fixed effects, does not change the result (Columns 2-4). Thus, we find no evidence that reform exposure reduces co-residence of parents with sons. ${ }^{49}$ This appears to be a sticky social norm, corroborating previous work on norms supporting gender inequality (Alesina, Giuliano and Nunn, 2013).

47 As mentioned earlier, NFHS data indicates that very few (less than 10\%) women are married before turning 14 .

48 Restricting the sample to married adult sons also helps us account for children's widespread residence with parents until marriage in India.

${ }^{49} \mathrm{We}$ do not find any impact on co-residence of parents with adult daughters (results available on request). 
To examine the impact of exposure to the reform on distance of married women from their natal home, we use a similar specification as Equation (4) where the dependent variable is a binary measure that takes the value 1 if the distance between a married woman's marital and natal homes is 10 kilometers or less and zero otherwise. ${ }^{50}$ We choose this threshold as it captures the lowest quartile of women's marriage distances in our sample. "Exposure to reform" is a dummy variable that equals 1 if the woman was 14 or younger at the time of reform and zero otherwise. The results are presented in Table 7. Women exposed to the reform are 3 percentage points (significant at 10 percent) more likely to marry into homes within 10 kilometers of their natal households (Column 2). We also find a barely significant effect in the same direction if we use 20 kilometers rather than 10 (Appendix Table A11). Thus, it appears that there was in fact some norm-shifting in terms of daughters marrying closer to home, although co-residence often coincides with the son working on the land and then inheriting it, so the latter is the more important, and the more rigid measure, of patrilocality.

To elaborate further, our results for co-residence show no erosion in the tradition of parents living with adult sons and these results alone are consistent with sex ratios being biased against girls. We find some weak but inconclusive (imprecise) evidence of adjustment post reform in the distance between daughters' natal and marital homes. While this may indicate that daughters want to move closer to natal property once they acquire rights over it, it may have little impact on parents' incentives if what parents need is effort (labour) on the property (often land), which is historically provided by co-resident sons. In other words, co-residence with sons may dominate parental incentives. Another explanation that would reconcile the result pertaining to married daughters potentially living closer with the result that parents continue to be averse to giving birth to (more than one) daughter(s) is that the compliers driving these two results may be different. In other words, families who commit female foeticide are different than those whose daughters marry closer to the natal home.

\section{Conclusion}

This paper shows that legislation that gives women equal rights to inheritance of ancestral property intensifies son preference in fertility. The evidence is stark, showing large increases in parents' proclivity to commit sex-selective abortion in order to manipulate the sex composition of their births in favour of sons. In fact, we find that parents also adjusted

50 We use the kilometer distance between the household sampled and each married woman's marital home. This measure includes female household heads, whose distance from their natal home is defined as zero for household heads who were born in their current home. 
the sex composition of their births in other ways: the reform was associated with an increase in girl relative to boy infant mortality and an increase in the tendency for families without a son (or their desired number of sons) to continue fertility. This is corroborated by evidence on increased reported son preference (i.e. stated desired share of sons among births) post reform.

Our findings demonstrate the challenges faced by legal reform. They suggest that support for institutionalizing women's economic rights was not widespread in India. Pervasive support (among men) has been argued to emerge as the returns to human capital investment rise (Doepke and Tertilt 2009). While a full analysis is beyond the scope of this paper, we observe that average returns to human capital have been rising in India since the 1990s, and that women's education has converged towards that of men. However, there remain barriers to women realizing returns to education on the labour market (Field et al. 2016). Moreover, we provide evidence that the convention that sons provide old-age security has not changed and there is no systematically provided state pension.

In Europe and America, the legislation of economic rights for women followed the implementation of women's suffrage. In India, women and men have had equal voting rights since India gained independence from British rule in 1947, but legislation of rights for women has proceeded only slowly since then. ${ }^{51}$ The early amendments to the Hindu Succession Act that we analyse in this paper were favoured by women legislators in seats reserved for lower castes, with women legislators from higher castes having no discernible impact on women-friendly laws (Clots-Figueras, 2011). It may be that consistent monitoring of implementation of legal change requires a larger share of women in government than currently occupy these positions in India (Brulé 2017). During 19802007 , for instance, $59 \%$ of women in contrast with $66 \%$ of men turned out to vote, but only $4.4 \%$ of electoral candidates for state legislative assemblies were women, and women comprised only 5.5\% of state legislatures (Bhalotra, Clots-Figueras and Iyer forthcoming).

\footnotetext{
51 The Dowry Prohibition Act of 1961 was among the first pro-female legislative reforms, followed by The Prevention of Sati (widow burning) Act of 1987 and the National Commission for Women Act 1990. The federal Inheritance Rights Reform and the Protection of Women Domestic Violence Act were passed as recently as 2005, and the Child Marriage Act was passed in 2006.
} 


\section{References}

Abrevaya, J. (2009) "Are There Missing Girls in the United States? Evidence from Birth Data." American Economic Journal: Applied Economics 1 (2): 1-34.

Agarwal, B. (1994) A Field of One's Own: Gender and Land Rights in South Asia, Cambridge University Press

Aldashev, G., J. Platteau and Z. Wahhaj (2011) "Legal Reform in the Presence of a Living Custom: An Economic Approach", Proceedings of the National Academy of Sciences, 22 December, 108 (Supplement 4) 21320-21325

Alesina, A., P. Giuliao and N. Nunn (2013) "On the Origins of Gender Roles: Women and the Plough.” The Quarterly Journal of Economics 128(2): 469-530

Almond, D. and L. Edlund (2008) "Son-Biased Sex Ratios in the 2000 United States Census." Proceedings of the National Academy of Sciences 105 (15): 5681-82

Almond, D., H. Li and S. Zhang (forthcoming) "Land Reform and Sex Selection in China" Journal of Political Economy. Available as NBER Working Paper No. 19153.

Anderson, S. (2003) "Why dowry payments declined with modernization in Europe but are rising in India", Journal of Political Economy, April 2003, Vol. 111, p. 269-310

Anderson, S. and G. Genicot (2015) "Suicides and Property Rights in India", Journal of Development Economics, Vol 114, pp. 64-78, May

Anderson, S. and D. Ray (2012) "The Age Distribution of Missing Women in India", Economic and Political Weekly, Vol. XLVII, No. 47-48, pp. 87-95

Anukriti, S., S. Bhalotra and H. Tam (2016) "On the Quantity and Quality of Girls: New Evidence on Abortion, Fertility, and Parental Investments", IZA Discussion Paper No. 10271

Arnold, F., M. K. Choe and T.K. Roy (1998) "Son Preference, the Family-building Process and Child Mortality in India", Population Studies, 52:3, 301-315

Ashraf, N., E. Field and J. Lee (2014) "Household Bargaining and Excess Fertility: An Experimental Study in Zambia." American Economic Review Vol. 104, No. 7

Banerjee, A., P. Gertler and M. Ghatak (2002) "Empowerment and Efficiency: Tenancy Reform in West Bengal" Journal of Political Economy, 110(2)

Baranov, V., S. Bhalotra, P. Biroli and J. Maselko (2017) “Maternal Depression, Women's Empowerment, and Parental Investment: Evidence from a Large Randomized Control Trial", IZA Discussion Paper No. 11187, November

Besley, T. (1995) "Property Rights and Investment Incentives: Theory and Evidence from Ghana", Journal of Political Economy, 103(5), pp. 903-937

Besley, T. and M. Ghatak (2009) "Property Rights and Economic Development" in Handbook of Development Economics eds. D. Rodrik and M. Rosenzweig, North Holland

Bhalotra, S. and T. Cochrane (2010) "Where Have All the Young Girls Gone? Identifying Sex-Selective Abortion in India", IZ A Discussion Paper No. 5381, December 
Bhalotra, S., A. Chakravarty, D. Mookherjee and F. J. Pino (forthcoming) "Property Rights and Gender Bias: Evidence from Land Reform in West Bengal", American Economic Journal: Applied Economics. An earlier version is available as IZA DP No. 9930.

Bhalotra, S., I. Clots-Figueras and L. Iyer (2018) "Religion and Abortion: The Role of Politician Identity", IZA DP No. 11292, January.

Bhalotra, S., I. Clots-Figueras and L. Iyer (forthcoming) "Pathbreakers: Women's Electoral Success and Future Political Participation", The Economic Journal

Bhalotra, S., A. Chakravarty and S. Gulesci (2016) "The Price of Gold: Dowry and Death in India”, IZA Discussion Paper No. 9679, January

Bhalotra S. and A. van Soest (2008), "Birth-Spacing, Fertility and Neonatal Mortality in India: Dynamics, Frailty, and Fecundity", Journal of Econometrics, Vol. 143, No. 2: 274-290

Bobonis, Gustavo J. (2009) "Is the Allocation of Resources within the Household Efficient? New Evidence from a Randomized Experiment," Journal of Political Economy, 117(3), 453-503

Botticini, M. and A. Siow (2003) "Why dowries?" The American Economic Review, 93(4):13851398

Brulé, R. (2017) "Reform, Representation and Resistance: The Politics of Property Rights' Enforcement," Working Paper. NYU Abu Dhabi. Available at: https://rachelbrule.files.wordpress.com/2017/10/20170613 rrr short notitle.pdf

Cameron, C. A., J. B Gelbach and D. L. Miller (2008) "Bootstrap-Based Improvements for Inference with Clustered Errors”, 90(3), pp. 414-427

Calvi, R., A. Lewbel and D. Tommasi (2017) “Women's Empowerment and Family Health: Estimating LATE with Mismeasured Treatment", available at SSRN: https://ssrn.com/abstract=2980250 or http://dx.doi.org/10.2139/ssrn.2980250

Chen, M. and J. Dreze (1992) "Widows and Health in Rural North India", Economic and Political Weekly Vol. 27, No. $43 / 44$ (Oct. 24-31), pp. WS81-WS92

Chung, W. and M. Dasgupta (2007) "Why is Son Preference Declining in South Korea ? The Role of Development and Public policy, and the Implications for China and India," Policy Research Working Paper Series No. 4373, World Bank

Clots-Figueras, Irma (2011) "Women in Politics: Evidence from the Indian States", Journal of Public Economics, 95(2011), pp. 664-690

Dahl, G. B. and E. Moretti (2008) "The Demand for Sons," Review of Economic Studies, 75 (4), pp. 1085-1120

Dasgupta, M. and P. N. Mari Bhat (1997) "Fertility Decline and Increased Manifestation of Sex Bias in India", Population Studies, Vol. 51, No. 3, pp. 307-315

Deininger, K. A. Goyal and H. Nagarajan (2013) "Women's Inheritance Rights and Intergenerational Transmission of Resources in India", Journal of Human Resources, 48(1)

Doepke, M. and M. Tertilt (2009) “Women's Liberation: What's in It for Men?”, Quarterly Journal of Economics, Volume 124, Issue 4, pp. 1541-1591 
Doepke, M., M. Tertilt and A. Voena (2012) “The Economics and Politics of Women's Rights", Annual Review of Economics, 4: 339-72

Duflo Esther and Christopher Udry, (2004) "Intrahousehold Resource Allocation in Cote d'Ivoire: Social Norms, Separate Accounts and Consumption Choices," NBER Working Papers 10498

Field, E. (2007) "Entitled to Work: Urban Property Rights and Labor Supply in Peru," Quarterly Journal of Economics, 122(4), pp. 1561-1602

Field, E., R. Pande, N. Rigol, S. Schaner and C. T. Moore (2016) "On Her Account: Can Strengthening Women's Financial Control Boost Female Labor Supply?”, mimeo

George, S. M. (2006) "Sex Ratio in India. Response to Jha et al." The Lancet, 27 May, Vol. 367, No. 9524: 1725

Ghatak, M. and S. Roy (2007) "Land Reform and Agricultural Productivity in India: A Review of the Evidence," Oxford Review of Economic Policy, Vol. 23(2), pp. 251-269

Goldstein, M. and C. Udry (2008) "The Profits of Power: Land Rights and Agricultural Investment in Ghana", Journal of Political Economy, Vol. 116, No. 6, pp. 981-1022

Goody, J. (1973) "Bridewealth and Dowry in Africa and Eurasia" in Bridewealth and Dowry (eds. J. Goody and S. J. Tambiah), pp. 1-58. Cambridge: Cambridge University Press

Government of India (2011) Census of India, 2011, Ministry of Home Affairs, New Delhi

Grover, A. and R. Vijayvergiya (2006) "Sex Ratio in India: Response to Prabhat Jha, Rajesh Kumar and Neeraj Dhingira”, The Lancet, 27 May-2 Vol. 367, No. 9524: 1726.

Guner, N (1998) "An Economic Analysis of Family Structure: Inheritance Rules and Marriage Systems", Working paper, University of Rochester

Htun, M. and L. Weldon (2011) "Sex Equality in Family Law: Historical Legacies, Feminist Activism and Religious Power in 70 Countries", Background Paper for the World Development Report 2012

Jayachandran, S. and I. Kuziemko (2011) "Why Do Mothers Breastfeed Girls Less Than Boys: Evidence and Implications for Child Health in India", Quarterly Journal of Economics, Vol. 126 (3), pp. 1485-1538

Jayaraman, R., D. Ray and S. Wang (2013) "Gender Differentials in the Seeking of Eye Care”, International Growth Centre Working Paper, April 2013

Joulfaian, D. (2006) “Inheritance and Saving”, NBER Working Paper No.12569, October

Landesa (2013) "Report on the Formal and Informal Barriers in the Implementation of the Hindu Succession (Amendment) Act 2005," UN Women, accessed online as of 13 December, 2017 at: http://www.landesa.org/wp-content/uploads/hsaa-study-report.pdf

Lundberg, S. J., R. A. Pollak and T. J. Wales (1997) "Do Husbands and Wives Pool Their Resources? Evidence from the United Kingdom Child Benefit," Journal of Human Resources, 32(3), pp. 463-480

Mahal, A., A. Varshney and S. Taman (2006) "Diffusion of Diagnostic Medical Devices and Policy Implications for India", International Journal of Technology Assessment in Health Care, Vol. 22, No. 02: 184-190 
Miller, B. (1981) The Endangered Sex: Neglect of Female Children in Rural North India, Cornell University Press, Ithaca

Miller, G. (2008) “Women's Suffrage, Political Responsiveness, and Child Survival in American History", The Quarterly Journal of Economics, Vol. 123(3), pp. 1287-1327

Milazzo, A. (2014) "Why are Adult Women Missing? Son Preference and Maternal Survival in India," World Bank Working Paper, March, pp. 1-53.

Murthy, L., V. Bal and D. Sharma (2006) "The Business of Sex Selection: The Ultrasonography Boom", Presented at the Nehru Memorial Museum \& Library Workshop on Declining Child Sex Ratio, January 23-24, New Delhi

Oster, E. (2009), "Proximate Sources of Population Sex Imbalance in India", Demography May 2009, Vol. 46, No. 325-339

Rosenblum, D. (2015) "Unintended Consequences of Women's Inheritance Rights on Female Mortality in India" (2015) Economic Development and Cultural Change, 63(2), pp. 223248

Rosenzweig, M. R. and K. I. Wolpin (1985) "Specific Experience, Household Structure, and Intergenerational Transfers: Farm Family Land and Labor Arrangements in Developing Countries", The Quarterly Journal of Economics, Vol. 100, Supplement (1985), pp. 961-987

Roy, S. (2015) "Empowering Women? Inheritance Rights, Female Education and Dowry Payments in India", Journal of Development Economics, Vol. 114, pp. 233-251, May

Sen, A. (1990) "More than 100 Million Women are Missing", The New York Review of Books, December 20

Sen, A. (2003) “Missing women-revisited”, BMJ, 327:1297

Sekher, T. (2012) "Ladlis and Lakshmis: Financial Incentive Schemes for the Girl Child," Economic and Political Weekly, XLVII

Sudha, S. and S. I. Rajan (1999) "Female Demographic Disadvantage in India 1981-1991: Sex Selective Abortions and Female Infanticide," Development and Change, 30 (3), pp. 585618

Thomas, D. (1990) “Intra-Household Resource Allocation: An Inferential Approach," The Journal of Human Resources, 25(4), pp. 635-664

Thomas, D. (1994) "Like Father, like Son; Like Mother, like Daughter: Parental Resources and Child Height," The Journal of Human Resources, 29 (4), 950

Topalova, P. (2010) "Factor Immobility and Regional Impacts of Trade Liberalization: Evidence on Poverty from India", American Economic Journal: Applied Economics, Vol. 2 (4), pp. 1-41

World Bank (2012) World Development Report 2012: Gender Equality and Development 


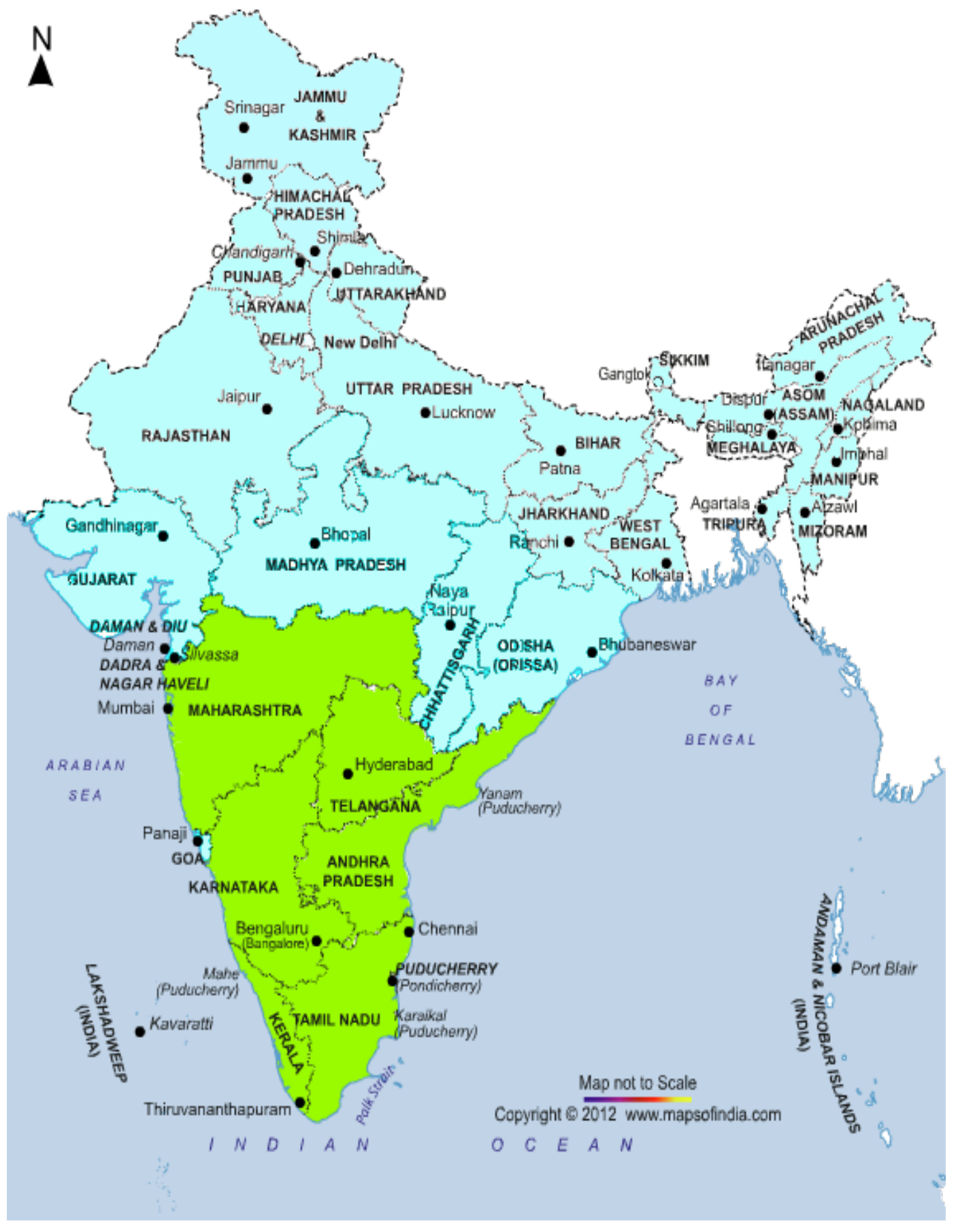

Figure 1: The Five Reforming States (in green) and rest of India (in blue)

Notes: The southern state of Andhra Pradesh split into two states - Andhra Pradesh and Telengana - in 2014. For the purposes of our analysis, these two are considered together as the undivided state of Andhra Pradesh that reformed in 1986. 
No. of domestically produced ultrasound machines

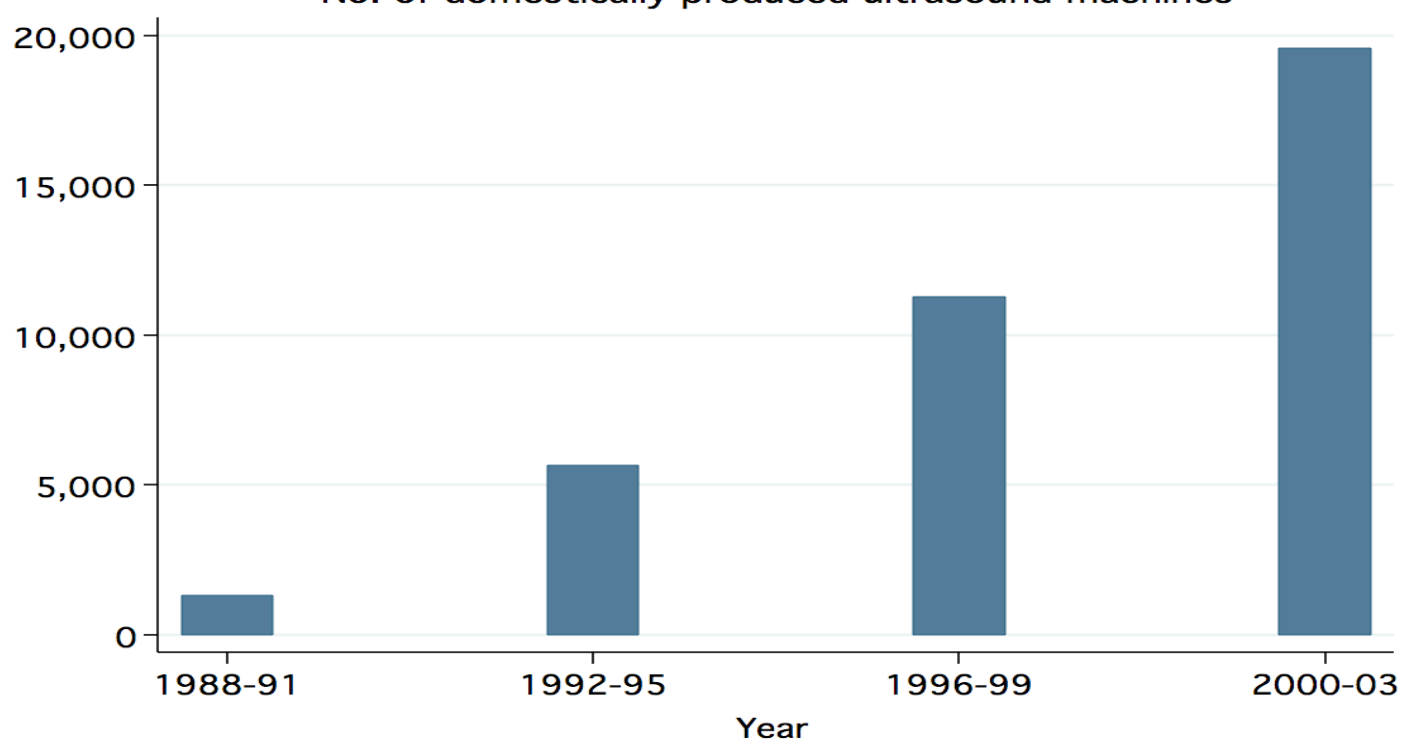

Figure 2a: Growth in availability of ultrasound machines (domestic)

Notes: The bars in the bottom graph plot the number of ultrasound machines produced domestically in India. Data Source: George (2006). Drawn from Anukriti et al. (2016).

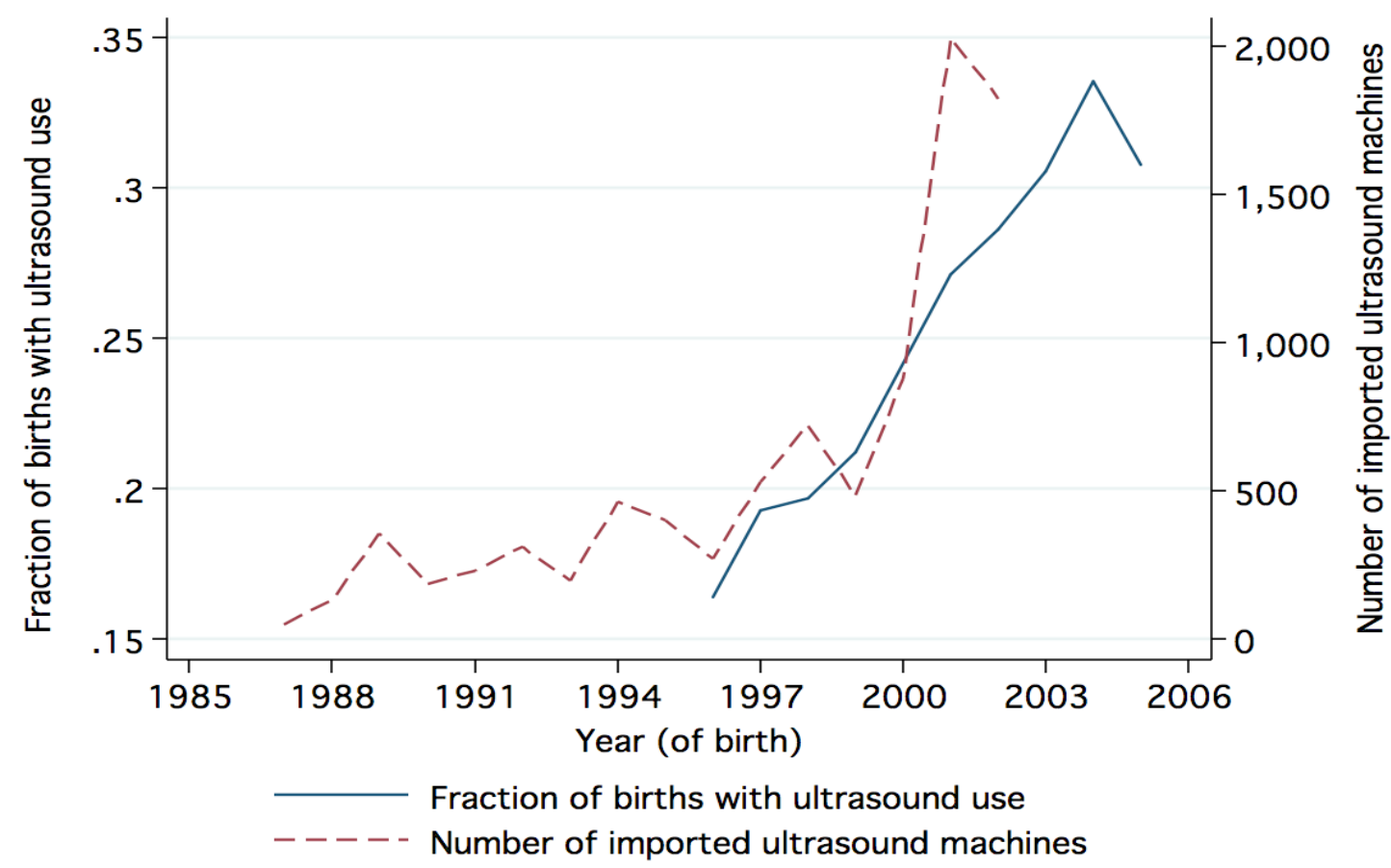

Figure 2b: Growth in availability of ultrasound machines (imported)

Notes: (1) The solid line in the top graph plots the fraction of births in a year for which the mother reports getting an ultrasound test at some point during the pregnancy (the denominator equals the number of births with a nonmissing response on ultrasound use). The relevant question was not asked in NFHS-1 but in NFHS-2 and NFHS-3, data on ultrasound use was collected for births since January 1995 and January 2001, respectively. The years 1995 and 2000 have been dropped due to extremely small sample sizes. (2) The dashed line in the top graph plots the number of ultrasound scanners imported at the national level, the first records of which appear in the import data in 1987; indeed, there was no category coding these scanners before then. Source: Mahal et al. (2006). Drawn from Anukriti et al. (2016). 


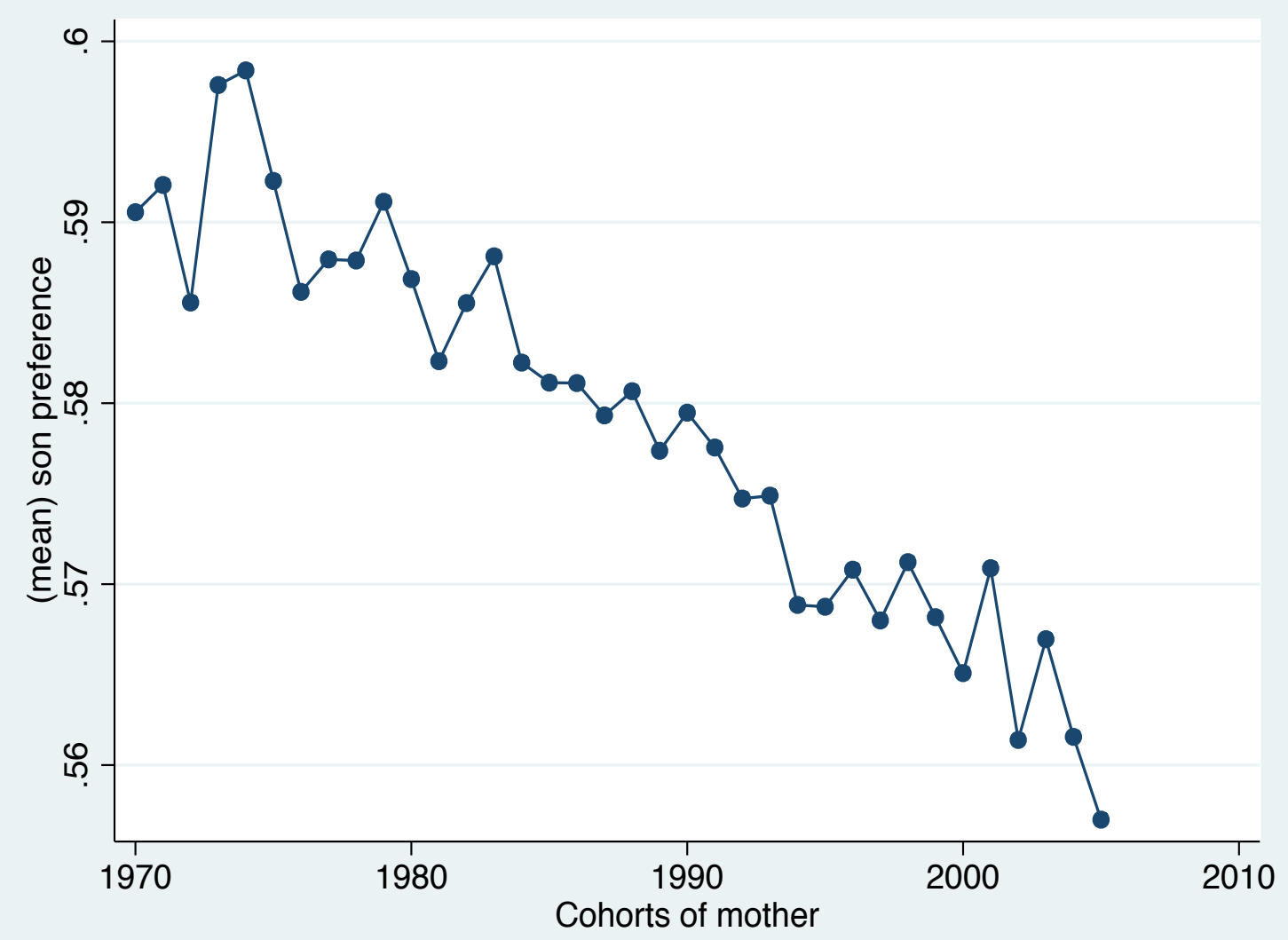

Figure 3: Trends in Reported Son Preference over time

Notes: NFHS data. Son preference in fertility reported by the mother. Time variation created by assuming that preferences as stated at any age of interview are shaped at age 20 . See the text for a discussion. 

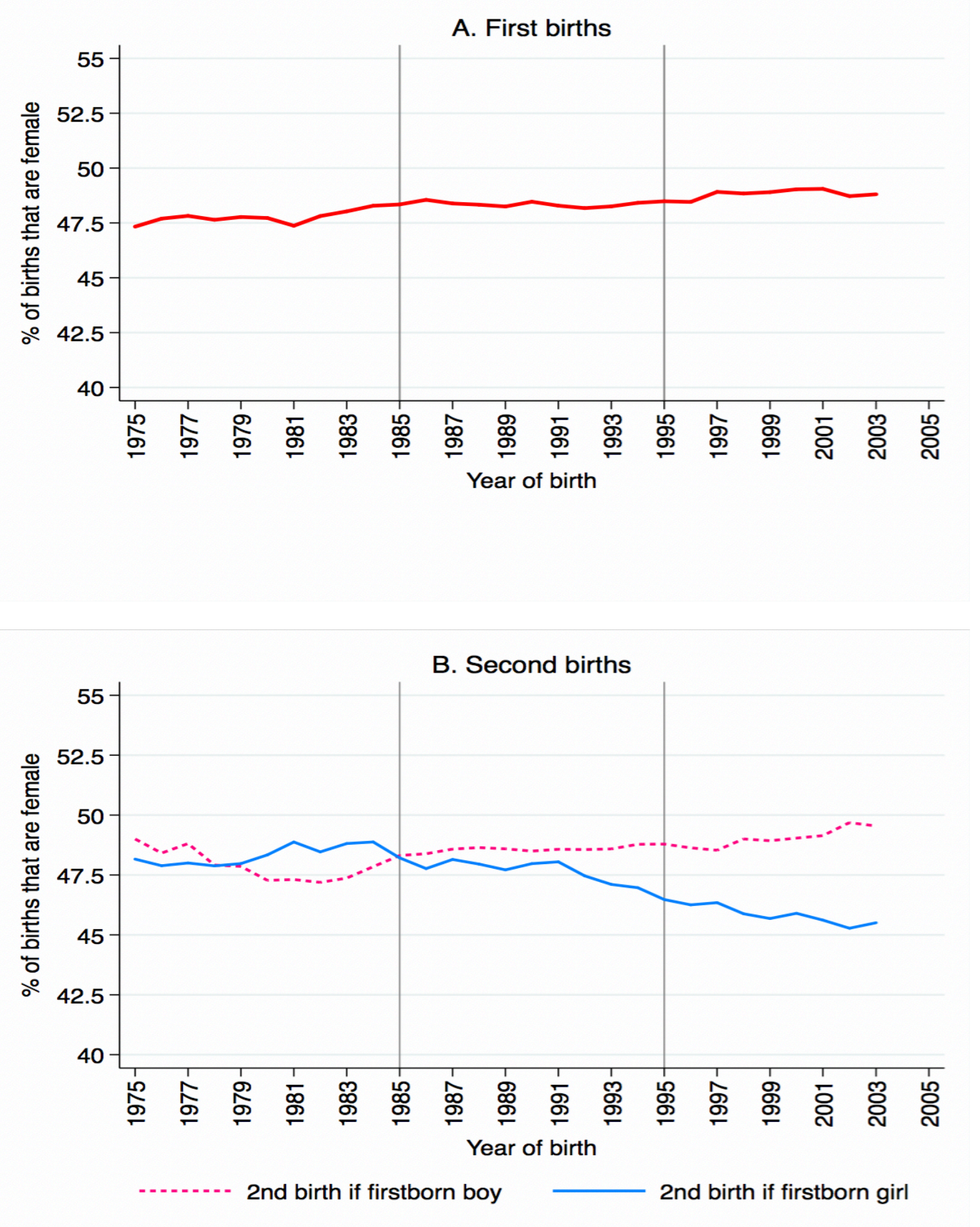

\section{Figure 4: Trends in proportion of females at birth (5-year moving averages)}

Notes: These plots are derived from Bhalotra and Cochrane (2010). Panel A shows the evolution of percent female among first births over time. Panel B plots the trend in percentage of births that are female for second births separately for families with firstborn son and firstborn daughter. In both cases, the $y$-axis shows the 5-year moving average of percentage of births that are female. Panel A show that, despite ultrasound availability, the sex ratio of first births has remained normal. 
Table 1: Sex Ratios at Birth

$\begin{array}{lllll}(1) & (2) & \text { (3) } & \text { (4) }\end{array}$

\begin{tabular}{|c|c|c|c|c|c|}
\hline \multirow[b]{2}{*}{ First-born is girl*Reform*p2 } & \multicolumn{2}{|c|}{ Child is female } & \multirow[b]{2}{*}{$-4.19 * *$} & \multirow[b]{2}{*}{$-4.28 * *$} & \multirow[b]{2}{*}{$-5.60 * * *$} \\
\hline & $-4.26 * *$ & $-4.22 * *$ & & & \\
\hline & $(1.54)$ & $(1.54)$ & $(1.54)$ & $(1.57)$ & $(1.64)$ \\
\hline \multirow[t]{2}{*}{ First-born is girl*Reform*p3 } & $-3.77 * *$ & $-3.60 * *$ & $-3.59 * *$ & $-3.54 * *$ & $-4.58 * *$ \\
\hline & $(1.51)$ & $(1.46)$ & $(1.46)$ & $(1.44)$ & $(1.91)$ \\
\hline Controls & No & Yes & Yes & Yes & No \\
\hline State fixed effects & Yes & Yes & Yes & Yes & No \\
\hline Child year of birth fixed effects & Yes & Yes & Yes & Yes & Yes \\
\hline State linear trends & No & No & Yes & No & Yes \\
\hline State-year of birth fixed effects & No & No & No & Yes & No \\
\hline Mother fixed effects & No & No & No & No & Yes \\
\hline $\mathrm{N}$ & 305741 & 301831 & 301831 & 301831 & 305741 \\
\hline
\end{tabular}

Notes: Robust standard errors, clustered at state-level, are in parentheses. ${ }^{*} p<0.10,{ }^{* *} p<0.05,{ }^{* * *} p<0.01$. This table uses NFHS data, is restricted to up to second births, with birth cohorts from 1972 to 2004 . The dependent variable is a dummy that equals 1 if birth is female and zero otherwise, multiplied by 100. "First-born is girl" is a dummy that equals 1 if the first-born child in the family is a girl, and zero otherwise. "Reform" is a dummy that equals 1 if the child is born after the reform in the reforming state and zero if they are born before the reform or in a non-reforming state. The reforming states are Kerala (1976), Andhra Pradesh (1986), Tamil Nadu (1989), Karnataka (1994) and Maharashtra (1994). "p2" and "p3" are dummy variables that capture the early (1985-94) and later (1995-2004) phases of ultrasound availability. Control variables include household wealth, parental education, urban dummy, religion dummies, high-caste dummy and age group categories of mother. With mother fixed effects, most of these controls are not identified since they do not vary within household, hence are not included. All necessary level and double-interaction terms are included but not reported (see Appendix Table A1 instead). 


\begin{tabular}{|c|c|c|c|c|c|c|}
\hline & (1) & $(2)$ & (3) & (4) & (5) & (6) \\
\hline & \multicolumn{6}{|c|}{ Child is female } \\
\hline & \multicolumn{2}{|c|}{ State Women's Commission } & \multirow{2}{*}{$\begin{array}{c}\text { Excluding } \\
\text { Maharashtra } \\
\text { and Karnataka }\end{array}$} & \multirow{2}{*}{$\begin{array}{c}\text { Only } \\
\text { Southern } \\
\text { States }\end{array}$} & \multicolumn{2}{|c|}{ completed fertility } \\
\hline & & & & & $\begin{array}{c}\text { mother } \\
\text { age }>=35\end{array}$ & $\begin{array}{c}\text { actual } \\
\text { fert. }>=\text { desi } \\
\text { red fert. }\end{array}$ \\
\hline \multirow[t]{2}{*}{ First-born is girl*Reform*p2 } & $-4.19 * *$ & $-4.19 * *$ & $-3.98 * *$ & & $-3.11 * *$ & $-2.97^{*}$ \\
\hline & $(1.54)$ & $(1.54)$ & $(1.67)$ & & (1.39) & (1.60) \\
\hline \multirow[t]{2}{*}{ First-born is girl*Reform*p3 } & $-3.59 * *$ & $-3.49 * *$ & -2.18 & & -2.93 & -1.86 \\
\hline & $(1.46)$ & $(1.44)$ & $(1.37)$ & & $(2.32)$ & (1.38) \\
\hline \multirow[t]{2}{*}{ State Commission } & 0.40 & 0.52 & & & & \\
\hline & $(0.50)$ & $(0.60)$ & & & & \\
\hline \multirow[t]{2}{*}{ First-born is girl*State Commission*p2 } & & 0.37 & & & & \\
\hline & & (1.47) & & & & \\
\hline First-born is girl*State Commission*p3 & & - & & & & \\
\hline \multirow[t]{2}{*}{ First-born girl*Reform*post } & & & & $-6.97 * *$ & & \\
\hline & & & & $(1.99)$ & & \\
\hline Controls & Yes & Yes & Yes & Yes & Yes & Yes \\
\hline State fixed effects & Yes & Yes & Yes & Yes & Yes & Yes \\
\hline Child year of birth fixed effects & Yes & Yes & Yes & Yes & Yes & Yes \\
\hline State linear trends & Yes & Yes & No & No & Yes & Yes \\
\hline State-year of birth fixed effects & No & No & Yes & Yes & No & No \\
\hline$N$ & 301831 & 301831 & 268594 & 73298 & 166561 & 233633 \\
\hline
\end{tabular}


Table 3: Reported Son Preference

\begin{tabular}{|c|c|c|c|c|}
\hline & (1) & $(2)$ & (3) & (4) \\
\hline & \multicolumn{4}{|c|}{ Son Preference } \\
\hline \multirow[t]{2}{*}{ First-born is girl*Reform*p2 } & $0.01 * *$ & $0.01 * *$ & $0.01 * *$ & $0.01 * * *$ \\
\hline & $(0.00)$ & $(0.00)$ & $(0.00)$ & $(0.00)$ \\
\hline \multirow{2}{*}{ First-born is girl*Reform*p3 } & $0.01 *$ & $0.01 *$ & $0.01 * *$ & $0.01 * *$ \\
\hline & $(0.00)$ & $(0.00)$ & $(0.00)$ & $(0.00)$ \\
\hline Controls & No & Yes & Yes & Yes \\
\hline State fixed effects & Yes & Yes & Yes & Yes \\
\hline Mother year of birth fixed effects & Yes & Yes & Yes & Yes \\
\hline State linear trends & No & No & Yes & No \\
\hline State-year of birth fixed effects & No & No & No & Yes \\
\hline $\mathrm{N}$ & 412039 & 406775 & 406775 & 406775 \\
\hline \multicolumn{5}{|c|}{$\begin{array}{l}\text { Notes: Robust standard errors, clustered at state-level, are in parentheses. }{ }^{*} p<0.10,{ }^{*} p<0.05, * * * p<0.01 . \text { This } \\
\text { table uses NFHS data and all births. The dependent variable is the ratio of desired/ideal number of sons over } \\
\text { desired/ideal number of total children as reported by the mother. This being measured only at the time of survey, } \\
\text { we construct a continuous measure of reported son preference based the age of the mother at the time of survey. } \\
\text { We assume that son preferences at age } 20 \text { determine fertility (and foeticide) choices (see discussion in text). Thus, } \\
\text { women aged } 20 \text { in } 1998 \text { define son preferences in } 1998, \text { while women aged } 40 \text { in } 1998 \text { defined son preferences in } \\
1978 \text { (since they were } 20 \text { years old in 1978). Since by construction, the dependent variable does not vary within } \\
\text { mother, we do not present results from a specification with mother fixed effects for reported son preference. For } \\
\text { details on other variables, see notes for Table } 1 \text {. All necessary level and double-interaction terms are included but } \\
\text { not reported (see Appendix Table A8 instead). }\end{array}$} \\
\hline
\end{tabular}

Table 4: Female Infant Mortality

\section{$(1)-(2)$}

(3)

Child dies before turning 1 year old

\begin{tabular}{|c|c|c|c|c|c|}
\hline First-born is girl*Reform*p2 & $\begin{array}{l}-1.59 * * * \\
(0.51)\end{array}$ & $\begin{array}{l}-1.44 * * \\
(0.58)\end{array}$ & $\begin{array}{l}-1.43^{* *} \\
(0.57)\end{array}$ & $\begin{array}{l}-1.37 * * \\
(0.57)\end{array}$ & $\begin{array}{l}-3.47^{* * *} \\
(1.01)\end{array}$ \\
\hline First-born is girl*Reform*p3 & $\begin{array}{l}-1.24^{* *} \\
(0.57)\end{array}$ & $\begin{array}{l}-1.15^{* *} \\
(0.54)\end{array}$ & $\begin{array}{l}-1.18^{* *} \\
(0.52)\end{array}$ & $\begin{array}{l}-1.19 * * \\
(0.52)\end{array}$ & $\begin{array}{l}-3.61^{* *} \\
(1.68)\end{array}$ \\
\hline First-born is girl*Reform*p2*female & $\begin{array}{l}3.17^{* * *} \\
(0.83)\end{array}$ & $\begin{array}{l}3.50 * * * \\
(0.84)\end{array}$ & $\begin{array}{l}3.47^{* * * *} \\
(0.83)\end{array}$ & $\begin{array}{l}3.39 * * * \\
(0.83)\end{array}$ & $\begin{array}{l}6.31^{* * *} \\
(2.20)\end{array}$ \\
\hline First-born is girl*Reform*p3*female & $\begin{array}{l}2.29 * * * \\
(0.74)\end{array}$ & $\begin{array}{l}2.57^{* * *} \\
(0.69)\end{array}$ & $\begin{array}{l}2.59 * * * \\
(0.68)\end{array}$ & $\begin{array}{l}2.55^{* * * *} \\
(0.69)\end{array}$ & $\begin{array}{l}6.31^{* * *} \\
(2.15)\end{array}$ \\
\hline Controls & No & Yes & Yes & Yes & No \\
\hline State fixed effects & Yes & Yes & Yes & Yes & No \\
\hline Child year of birth fixed effects & Yes & Yes & Yes & Yes & Yes \\
\hline State linear trends & No & No & Yes & No & Yes \\
\hline State-year of birth fixed effects & No & No & No & Yes & No \\
\hline Mother fixed effects & No & No & No & No & Yes \\
\hline $\mathrm{N}$ & 305741 & 301831 & 301831 & 301831 & 301831 \\
\hline
\end{tabular}

Notes: Robust standard errors, clustered at state-level, are in parentheses. ${ }^{*} p<0.10,{ }^{* *} p<0.05,{ }^{* * *} p<0.01$. This table uses NFHS data, is restricted to up to second births, with birth cohorts from 1972 to 2004 . The dependent variable captures whether the child died on or before their first birthday, multiplied by 100. "female" is a dummy that captures if the index child is a girl. For details on sample and variables, see notes for Table 1. All necessary level and double-interaction terms are included but not reported (see Appendix Table A9 instead). 
Table 5: Fertility

\begin{tabular}{|c|c|c|c|c|c|}
\hline & (1) & $(2)$ & (3) & (4) & (5) \\
\hline & \multicolumn{5}{|c|}{ Has younger sibling } \\
\hline \multirow[t]{2}{*}{ First-born is girl*Reform*p2 } & 3.30 & 2.52 & 2.59 & 2.45 & 3.28 \\
\hline & $(3.90)$ & (3.79) & (3.78) & $(3.84)$ & $(4.68)$ \\
\hline \multirow[t]{2}{*}{ First-born is girl*Reform*p3 } & $8.56 * * *$ & $8.10 * * *$ & $8.19 * * *$ & $7.90 * * *$ & $12.33 * * *$ \\
\hline & $(1.96)$ & $(2.00)$ & $(1.98)$ & $(2.07)$ & $(2.94)$ \\
\hline Controls & No & Yes & Yes & Yes & No \\
\hline State fixed effects & Yes & Yes & Yes & Yes & No \\
\hline Child year of birth fixed effects & Yes & Yes & Yes & Yes & Yes \\
\hline State linear trends & No & No & Yes & No & Yes \\
\hline State-year of birth fixed effects & No & No & No & Yes & No \\
\hline Mother fixed effects & No & No & No & No & Yes \\
\hline $\mathrm{N}$ & 305741 & 301831 & 301831 & 301831 & 305741 \\
\hline
\end{tabular}

Notes: Robust standard errors, clustered at state-level, are in parentheses. ${ }^{*} p<0.10,{ }^{* *} p<0.05,{ }^{* * *} p<0.01$. This table uses NFHS data, is restricted to up to second births, with birth cohorts from 1972 to 2004 . The dependent variable captures whether the child has younger brothers or sisters, multiplied by 100 . For details on sample and variables, see notes for Table 1 . All necessary level and double-interaction terms are included but not reported (see Appendix Table A10 instead).

Table 6. Co-residence of Parents and Adult Sons

\begin{tabular}{|c|c|c|c|c|}
\hline & (1) & $(2)$ & (3) & (4) \\
\hline & \multicolumn{4}{|c|}{ Parent Resides with Adult Son } \\
\hline \multirow[t]{2}{*}{ Exposure to reform } & -0.01 & -0.01 & -0.01 & -0.02 \\
\hline & $(0.01)$ & $(0.01)$ & $(0.01)$ & $(0.01)$ \\
\hline Controls & Yes & Yes & Yes & Yes \\
\hline State fixed effects & Yes & Yes & Yes & Yes \\
\hline Year of birth fixed effects & Yes & Yes & Yes & Yes \\
\hline State linear trends & No & No & Yes & No \\
\hline State-year of birth fixed effects & No & No & No & Yes \\
\hline Married sons only & No & Yes & Yes & Yes \\
\hline N & 16392 & 13820 & 13820 & 13820 \\
\hline \multicolumn{5}{|c|}{$\begin{array}{l}\text { Notes: Robust standard errors, clustered at state-level, are in parentheses. }{ }^{*} p<0.10,{ }^{* *} p<0.05, * * * p<0.01 . \text { This } \\
\text { table uses REDS data, includes all adult (aged } 18 \text { or older) sons born before } 2005 \text { in families with at least one living } \\
\text { parent. The dependent variable is a binary indicator of whether or not a given son is residing with a parent. } \\
\text { "Exposure to reform" is a dummy variable which equals } 1 \text { if there is a sister in the given son's generation who was } \\
14 \text { years or less at the time of reform in the reforming state and zero otherwise. Our measure includes two } \\
\text { generations of sons: first, the household head and siblings, and second, the household head's children. Control } \\
\text { variables include household size, land ownership, and education. Mother fixed effects are not included in this table } \\
\text { because of limited within-mother variation in births spanning treatment periods. }\end{array}$} \\
\hline
\end{tabular}


(1) (2) $\quad(3)$

Marital \& Natal Homes<10km Apart

\begin{tabular}{lccc}
\hline Exposure to reform & 0.02 & $0.03^{*}$ & 0.00 \\
& $(0.02)$ & $(0.02)$ & $(0.02)$ \\
\hline Controls & No & Yes & Yes \\
State fixed effects & Yes & Yes & Yes \\
Year of birth fixed effects & Yes & Yes & Yes \\
State linear trends & No & No & Yes \\
\hline $\mathrm{N}$ & 43035 & 37283 & 37283 \\
\hline
\end{tabular}

Notes: Robust standard errors, clustered at state-level, are in parentheses. ${ }^{*} \mathrm{p}<0.10,{ }^{*} \mathrm{p}<0.05$,

$* * * \mathrm{p}<0.01$. This table uses REDS data, and includes all married women born before 2005. The dependent variable is a binary indicator of whether or not there are at most $10 \mathrm{~km}$ between a given woman's natal and marital homes. "Exposure to reform" is a dummy that equals 1 if the given woman was 14 years or younger at the time of reform in the reforming states and zero otherwise. Control variables include household wealth, parental education, religion dummies, high-caste dummy and age group categories of the mother. Mother fixed effects are not included in this table because of limited within-mother variation in births spanning treatment periods. 
Table 8: Test of balance in samples by first-born sex

\begin{tabular}{|c|c|c|c|}
\hline & first-born is boy & first-born is girl & Difference \\
\hline & (1) & $(2)$ & (3) \\
\hline \multirow[t]{2}{*}{ Rural } & 0.64 & 0.64 & -0.00 \\
\hline & $(0.48)$ & $(0.48)$ & {$[0.00]$} \\
\hline \multirow[t]{2}{*}{ Hindu } & 0.76 & 0.76 & -0.00 \\
\hline & $(0.43)$ & $(0.42)$ & {$[0.00]$} \\
\hline \multirow[t]{2}{*}{ Muslim } & 0.11 & 0.11 & -0.00 \\
\hline & $(0.31)$ & $(0.31)$ & {$[0.00]$} \\
\hline \multirow[t]{2}{*}{ High caste Hindu } & 0.38 & 0.37 & 0.00 \\
\hline & $(0.48)$ & $(0.48)$ & {$[0.00]$} \\
\hline \multicolumn{4}{|l|}{ Parental education } \\
\hline \multirow[t]{2}{*}{ Mother has secondary or higher education } & 0.12 & 0.12 & 0.00 \\
\hline & $(0.32)$ & $(0.32)$ & {$[0.00]$} \\
\hline \multirow[t]{2}{*}{ Father has secondary or higher education } & 0.21 & 0.21 & 0.00 \\
\hline & $(0.41)$ & $(0.41)$ & {$[0.00]$} \\
\hline \multicolumn{4}{|l|}{ Mother's birth cohort } \\
\hline \multirow[t]{2}{*}{$1942-1960$} & 0.03 & 0.03 & 0.00 \\
\hline & $(0.18)$ & $(0.18)$ & {$[0.00]$} \\
\hline \multirow[t]{2}{*}{ 1954-1979 } & 0.88 & 0.88 & 0.00 \\
\hline & $(0.33)$ & $(0.33)$ & {$[0.00]$} \\
\hline \multirow[t]{2}{*}{ 1980-1987 } & 0.09 & 0.09 & -0.00 \\
\hline & $(0.28)$ & $(0.29)$ & {$[0.00]$} \\
\hline \multicolumn{4}{|l|}{ Mother's age at birth } \\
\hline \multirow[t]{2}{*}{$12-15$} & 0.11 & 0.10 & 0.00 \\
\hline & $(0.31)$ & $(0.31)$ & {$[0.00]$} \\
\hline \multirow[t]{2}{*}{$16-18$} & 0.32 & 0.32 & 0.00 \\
\hline & $(0.47)$ & $(0.46)$ & {$[0.00]$} \\
\hline \multirow[t]{2}{*}{$19-24$} & 0.47 & 0.47 & -0.00 \\
\hline & $(0.50)$ & $(0.50)$ & {$[0.00]$} \\
\hline \multirow[t]{2}{*}{$25-30$} & 0.09 & 0.09 & -0.00 \\
\hline & $(0.29)$ & $(0.29)$ & {$[0.00]$} \\
\hline \multirow[t]{2}{*}{$31-49$} & 0.01 & 0.01 & 0.00 \\
\hline & $(0.11)$ & $(0.11)$ & {$[0.00]$} \\
\hline \multirow[t]{2}{*}{ Top $20 \%$ by wealth } & 0.24 & 0.24 & 0.00 \\
\hline & $(0.43)$ & $(0.43)$ & {$[0.00]$} \\
\hline N (1st births) & 87760 & 81968 & 169728 \\
\hline
\end{tabular}


Online Appendix A: Additional Tables

Table A1: Sex Ratios at Birth: Full Specification

\begin{tabular}{|c|c|c|c|c|c|c|}
\hline & $(1)$ & $(2)$ & (3) & (4) & (5) & (6) \\
\hline & \multicolumn{6}{|c|}{ Child is female } \\
\hline \multirow[t]{2}{*}{ First-born is girl } & $0.88 * *$ & $0.94 * *$ & $0.80^{*}$ & $0.80^{*}$ & $0.84^{*}$ & - \\
\hline & $(0.42)$ & $(0.42)$ & $(0.42)$ & $(0.42)$ & $(0.42)$ & \\
\hline \multirow[t]{2}{*}{ First-born is girl*p2 } & $-1.46 * *$ & $-1.50 * * *$ & $-1.42 * *$ & $-1.42 * *$ & $-1.47 * * *$ & $-3.33 * * *$ \\
\hline & $(0.53)$ & $(0.52)$ & $(0.52)$ & $(0.52)$ & $(0.52)$ & $(0.90)$ \\
\hline \multirow[t]{2}{*}{ First-born is girl*p3 } & $-4.13 * * *$ & $-4.19 * * *$ & $-4.08 * * *$ & $-4.09 * * *$ & $-4.19 * * *$ & $-9.17 * * *$ \\
\hline & $(0.82)$ & $(0.83)$ & $(0.83)$ & $(0.83)$ & $(0.83)$ & $(1.38)$ \\
\hline \multirow[t]{2}{*}{ Reform } & $0.46 * *$ & $-0.76 * *$ & $-0.96 * *$ & $-3.11 * * *$ & - & 1.12 \\
\hline & $(0.22)$ & $(0.35)$ & $(0.37)$ & $(0.59)$ & & (0.89) \\
\hline \multirow[t]{2}{*}{ Reform*p2 } & 0.08 & 0.69 & $0.90 *$ & $2.65^{* * *}$ & - & $-2.08 * * *$ \\
\hline & $(0.26)$ & $(0.47)$ & $(0.50)$ & $(0.55)$ & & $(0.74)$ \\
\hline \multirow[t]{2}{*}{ Reform*p3 } & -0.11 & 0.40 & 0.66 & $2.48 * * *$ & - & -3.42 \\
\hline & $(0.44)$ & $(0.48)$ & $(0.54)$ & $(0.81)$ & & $(2.15)$ \\
\hline \multirow[t]{2}{*}{ First-born is girl*Reform } & $4.93 * * *$ & $4.88 * * *$ & $4.73 * * *$ & $4.71^{* * *}$ & $4.74 * * *$ & $6.72 * * *$ \\
\hline & $(0.42)$ & $(0.43)$ & $(0.43)$ & $(0.43)$ & $(0.42)$ & $(0.80)$ \\
\hline \multirow[t]{2}{*}{ First-born is girl*Reform*p2 } & $-4.30 * * *$ & $-4.26 * *$ & $-4.22 * *$ & $-4.19 * *$ & $-4.28 * *$ & $-5.60 * * *$ \\
\hline & $(1.51)$ & $(1.54)$ & $(1.54)$ & $(1.54)$ & $(1.57)$ & $(1.64)$ \\
\hline \multirow[t]{2}{*}{ First-born is girl*Reform*p3 } & $-3.83^{* *}$ & $-3.77^{* *}$ & $-3.60 * *$ & $-3.59 * *$ & $-3.54 * *$ & $-4.58 * *$ \\
\hline & $(1.50)$ & $(1.51)$ & $(1.46)$ & $(1.46)$ & $(1.44)$ & $(1.91)$ \\
\hline \multirow[t]{2}{*}{ p2 } & $0.57 * *$ & & & & & \\
\hline & $(0.21)$ & & & & & \\
\hline \multirow[t]{2}{*}{ p3 } & $0.99 * * *$ & & & & & \\
\hline & $(0.33)$ & & & & & \\
\hline \multirow[t]{2}{*}{ Constant } & $47.76 * * *$ & & & & & \\
\hline & $(0.22)$ & & & & & \\
\hline Controls & No & No & Yes & Yes & Yes & No \\
\hline State fixed effects & No & Yes & Yes & Yes & Yes & No \\
\hline Child year of birth fixed effects & No & Yes & Yes & Yes & Yes & Yes \\
\hline State linear trends & No & No & No & Yes & No & Yes \\
\hline State-year of birth fixed effects & No & No & No & No & Yes & No \\
\hline Mother fixed effects & No & No & No & No & No & Yes \\
\hline $\mathrm{N}$ & 305741 & 305741 & 301831 & 301831 & 301831 & 305741 \\
\hline \multicolumn{7}{|c|}{$\begin{array}{l}\text { Notes: Robust standard errors, clustered at state-level, are in parentheses. }{ }^{*} p<0.10,{ }^{*} p<0.05, * * * p<0.01 \text {. This table uses NFHS data, } \\
\text { is restricted to up to second births, with birth cohorts from } 1972 \text { to } 2004 \text {. For details on sample and variables, see notes for Table } 1 \text {. In } \\
\text { column } 5 \text {, the level effect of the reform as well as its interactions with the } \mathrm{p} 2 \text { (early ultrasound) and } \mathrm{p} 3 \text { (late ultrasound) dummies are } \\
\text { no longer identified after the inclusion of state-year of birth fixed effects. In column } 6 \text {, girl1 is no longer identified after the inclusion of } \\
\text { mother fixed effects. In all the columns, the coefficient on first-born is girl }{ }^{*} \text { reform is likely to capture a "Kerala effect", since Kerala was } \\
\text { the only state to reform pre-ultrasound. }\end{array}$} \\
\hline
\end{tabular}


Table A2a: Sex Ratios at Birth: Including up to Third Births

\begin{tabular}{|c|c|c|c|c|c|}
\hline & $(1)$ & $(2)$ & $(3)$ & $(4)$ & $(5)$ \\
\hline & \multicolumn{5}{|c|}{ Child is female } \\
\hline \multirow[t]{2}{*}{ First-born is girl*Reform*p2 } & $-1.85^{*}$ & $-1.88^{*}$ & $-1.86^{*}$ & $-1.82 *$ & -2.55 \\
\hline & $(1.06)$ & $(1.07)$ & $(1.07)$ & $(1.07)$ & $(1.51)$ \\
\hline \multirow[t]{2}{*}{ First-born is girl*Reform*p3 } & -1.86 & -1.83 & -1.84 & -1.80 & -0.22 \\
\hline & $(1.40)$ & $(1.39)$ & $(1.38)$ & $(1.37)$ & $(1.68)$ \\
\hline Controls & No & Yes & Yes & Yes & No \\
\hline State fixed effects & Yes & Yes & Yes & Yes & No \\
\hline Child year of birth fixed effects & Yes & Yes & Yes & Yes & Yes \\
\hline State linear trends & No & No & Yes & No & Yes \\
\hline State-year of birth fixed effects & No & No & No & Yes & No \\
\hline Mother fixed effects & No & No & No & No & Yes \\
\hline $\mathrm{N}$ & 393518 & 388505 & 388505 & 388505 & 393518 \\
\hline
\end{tabular}

Table A2b: Sex Ratios at Birth: Including up to Fourth Births

\begin{tabular}{lccccc}
\hline & $(1)$ & $(2)$ & $(3)$ & $(4)$ & $(5)$ \\
\cline { 2 - 6 } & $-1.65^{*}$ & -1.63 & -1.62 & -1.63 & -1.51 \\
\hline First-born is girl*Reform*p2 & $(0.95)$ & $(0.99)$ & $(0.99)$ & $(0.98)$ & $(1.32)$ \\
& -1.41 & -1.36 & -1.37 & -1.37 & 2.11 \\
First-born is girl*Reform*p3 & $(1.22)$ & $(1.21)$ & $(1.21)$ & $(1.20)$ & $(1.38)$ \\
\hline Controls & No & Yes & Yes & Yes & No \\
State fixed effects & Yes & Yes & Yes & Yes & No \\
Child year of birth fixed effects & Yes & Yes & Yes & Yes & Yes \\
State linear trends & No & No & Yes & No & Yes \\
State-year of birth fixed effects & No & No & No & Yes & No \\
Mother fixed effects & No & No & No & No & Yes \\
\hline N & 442923 & 437274 & 437274 & 437274 & 442923 \\
\hline
\end{tabular}

Notes: Same as above. Sample restricted up to fourth births.

Table A2c: Sex ratio at Birth: First Births

\begin{tabular}{lc}
\hline & Child is female \\
\hline Reform & 0.08 \\
& $(0.20)$ \\
Reform*p2 & 0.50 \\
& $(0.37)$ \\
Reform*p3 & 0.84 \\
& $(0.53)$ \\
p2 & $0.46^{*}$ \\
& $(0.24)$ \\
p3 & $0.73^{*} *$ \\
& $(0.30)$ \\
Constant & $47.81^{* * *}$ \\
& $(0.20)$ \\
\hline N & 169728 \\
\hline Notes: Same as above. Sample restricted first births only.
\end{tabular}

Table A3: Sex Ratios at Birth: Hindu-landed, only reform 


\begin{tabular}{|c|c|c|c|c|}
\hline & (1) & (2) & (3) & (4) \\
\hline & \multicolumn{4}{|c|}{ Child is female } \\
\hline \multirow[t]{2}{*}{ First-born is girl } & -0.46 & -0.51 & -0.51 & -0.50 \\
\hline & $(0.75)$ & $(0.76)$ & $(0.76)$ & $(0.76)$ \\
\hline \multirow[t]{2}{*}{ Reform } & -1.23 & -1.16 & -1.77 & - \\
\hline & (1.16) & $(1.20)$ & $(1.48)$ & \\
\hline \multirow[t]{2}{*}{ First-born is girl*Reform } & 1.18 & 1.17 & 1.17 & 1.15 \\
\hline & $(2.60)$ & $(2.53)$ & $(2.53)$ & (2.59) \\
\hline \multirow[t]{2}{*}{ Hindu } & -0.13 & -0.52 & -0.52 & -0.46 \\
\hline & $(0.41)$ & $(0.53)$ & $(0.53)$ & $(0.53)$ \\
\hline \multirow[t]{2}{*}{ First-born is girl*Hindu } & -1.07 & -1.22 & -1.21 & -1.27 \\
\hline & $(0.74)$ & $(0.77)$ & $(0.77)$ & $(0.76)$ \\
\hline \multirow[t]{2}{*}{ Reform*Hindu } & 1.22 & 1.14 & 1.08 & 0.95 \\
\hline & $(0.83)$ & $(0.85)$ & $(0.83)$ & $(0.84)$ \\
\hline \multirow[t]{2}{*}{ First-born is girl*Reform*Hindu } & 0.16 & 0.33 & 0.32 & 0.37 \\
\hline & $(1.74)$ & $(1.72)$ & $(1.72)$ & $(1.77)$ \\
\hline \multirow[t]{2}{*}{ Land } & -0.11 & -0.23 & -0.20 & -0.21 \\
\hline & $(0.74)$ & $(0.77)$ & $(0.77)$ & $(0.78)$ \\
\hline \multirow[t]{2}{*}{ First-born is girl*Land } & 0.04 & 0.06 & 0.05 & 0.13 \\
\hline & $(1.36)$ & $(1.38)$ & $(1.38)$ & $(1.42)$ \\
\hline \multirow[t]{2}{*}{ Reform*Land } & -2.17 & -2.18 & -2.25 & -2.08 \\
\hline & $(1.55)$ & (1.63) & $(1.62)$ & $(1.67)$ \\
\hline \multirow[t]{2}{*}{ First-born is girl* Reform*Land } & 1.10 & 1.10 & 1.14 & 0.88 \\
\hline & $(2.44)$ & (2.39) & $(2.37)$ & $(2.48)$ \\
\hline \multirow[t]{2}{*}{ Hindu*Land } & 0.20 & 0.14 & 0.14 & 0.15 \\
\hline & $(0.73)$ & $(0.74)$ & $(0.74)$ & $(0.75)$ \\
\hline \multirow[t]{2}{*}{ First-born is girl*Hindu*Land } & 0.95 & 1.06 & 1.04 & 1.01 \\
\hline & $(1.46)$ & $(1.47)$ & (1.47) & $(1.51)$ \\
\hline \multirow[t]{2}{*}{ Reform*Hindu*Land } & 2.40 & 2.47 & 2.50 & 2.28 \\
\hline & $(1.51)$ & $(1.58)$ & $(1.58)$ & $(1.66)$ \\
\hline \multirow[t]{2}{*}{ First-born is girl*Reform*Hindu*Land } & $-3.64^{*}$ & $-3.91 * *$ & $-3.92 * *$ & $-3.75^{*}$ \\
\hline & $(1.85)$ & $(1.81)$ & $(1.79)$ & $(1.90)$ \\
\hline Controls & No & Yes & Yes & Yes \\
\hline State fixed effects & Yes & Yes & Yes & Yes \\
\hline Cohort fixed effects & Yes & Yes & Yes & Yes \\
\hline State linear trends & No & No & Yes & No \\
\hline State-year fixed effects & No & No & No & Yes \\
\hline $\mathrm{N}$ & 267982 & 264714 & 264714 & 264714 \\
\hline \multicolumn{5}{|c|}{$\begin{array}{l}\text { Notes: Robust standard errors, clustered at state-level, are in parentheses. }{ }^{*} p<0.10,{ }^{* *} p<0.05,{ }^{* *} p<0.01 \text {. This table } \\
\text { uses NFHS data, is restricted to up to second births, with birth cohorts from } 1972 \text { to } 2004 \text {. The dependent variable is a } \\
\text { dummy that equals } 1 \text { if birth is female and zero otherwise, multiplied by } 100 \text {. "First-born is girl" is a dummy that equals } \\
1 \text { if the first-born child in the family is a girl, and zero otherwise. "Reform" is a dummy that equals } 1 \text { if the child is born } \\
\text { after the reform in the reforming state and zero if they are born before the reform or in a non-reforming state. The } \\
\text { reforming states are Kerala (1976), Andhra Pradesh (1986), Tamil Nadu (1989), Karnataka (1994) and Maharashtra } \\
\text { (1994). "Hindu" is a dummy that equals } 1 \text { if the household religion is Hindu, Buddhist, Sikh or Jain and zero otherwise. } \\
\text { "Land" is a dummy that equals } 1 \text { if the household own land and zero otherwise. Control variables include household } \\
\text { wealth, parental education, urban dummy, high-caste dummy and age group categories of mother. In column } 4 \text {, the } \\
\text { level effect of the reform is no longer identified after the inclusion of state-year of birth fixed effects. }\end{array}$} \\
\hline
\end{tabular}


Table A4a: Sex Ratios at Birth: Using Alternative dataset REDS 2006

\begin{tabular}{|c|c|c|c|c|c|}
\hline & (1) & (2) & (3) & (4) & (5) \\
\hline & \multicolumn{5}{|c|}{ Child is female } \\
\hline \multirow[t]{2}{*}{ First-born is girl*Reform*post } & $-7.89 * *$ & $-7.63^{*}$ & -6.94 & -6.94 & $-8.30^{*}$ \\
\hline & $(3.32)$ & (3.77) & $(4.26)$ & $(4.27)$ & $(4.75)$ \\
\hline Controls & No & No & Yes & Yes & Yes \\
\hline State fixed effects & No & Yes & Yes & Yes & Yes \\
\hline Child year of birth fixed effects & No & Yes & Yes & Yes & Yes \\
\hline State linear trends & No & No & No & Yes & No \\
\hline State-year of birth fixed effects & No & No & No & No & Yes \\
\hline $\mathrm{N}$ & 11715 & 11715 & 10672 & 10672 & 10672 \\
\hline \multicolumn{6}{|c|}{$\begin{array}{l}\text { Notes: Robust standard errors, clustered at state-level, are in parentheses. }{ }^{*} p<0.10,{ }^{* *} p<0.05,{ }^{* * *} p<0.01 \text {. This table } \\
\text { uses REDS data, and is restricted up to second births. Due to smaller number of observations in REDS } 2006 \text { compared } \\
\text { to NFHS, we combine the two ultrasound periods into a single "Post" dummy variable that captures the full ultrasound } \\
\text { period } 1985-2004 \text {. Control variables include household wealth, parental education, religion dummies, high-caste } \\
\text { dummy and age group categories of mother. For details on the rest of variables, see notes for Table } 1 \text {. Mother fixed } \\
\text { effects are not included in this table because of limited within-mother variation in births spanning treatment periods. }\end{array}$} \\
\hline
\end{tabular}

Table A4b: Sex Ratios at Birth: Robustness Checks: Using Alternative dataset REDS 2006

\begin{tabular}{|c|c|c|c|c|c|}
\hline & (1) & $(2)$ & (3) & (4) & (5) \\
\hline & \multicolumn{5}{|c|}{ Child is female } \\
\hline & \multicolumn{2}{|c|}{$\begin{array}{l}\text { State Women's } \\
\text { Commission }\end{array}$} & \multirow{2}{*}{$\begin{array}{l}\text { Excluding } \\
\text { Maharashtra } \\
\text { and } \\
\text { Karnataka }\end{array}$} & \multirow{2}{*}{$\begin{array}{c}\text { Only } \\
\text { Southern } \\
\text { States }\end{array}$} & $\begin{array}{l}\text { completed } \\
\text { fertility }\end{array}$ \\
\hline & & & & & $\begin{array}{l}\text { mother } \\
\text { age }>=35\end{array}$ \\
\hline \multirow[t]{2}{*}{ First-born is girl*Reform*post } & $-7.64^{*}$ & -6.95 & $-13.92 * * *$ & -12.39 & $-11.43 * *$ \\
\hline & $(3.82)$ & $(4.28)$ & $(3.38)$ & $(7.02)$ & $(4.40)$ \\
\hline \multirow[t]{2}{*}{ State Commission } & 1.29 & 0.87 & & & \\
\hline & $(1.97)$ & (2.11) & & & \\
\hline Controls & No & Yes & Yes & Yes & Yes \\
\hline State fixed effects & Yes & Yes & No & No & Yes \\
\hline Child year of birth fixed effects & Yes & Yes & Yes & Yes & Yes \\
\hline State linear trends & Yes & Yes & No & No & Yes \\
\hline Female*state linear trends & No & No & No & No & No \\
\hline State-year of birth fixed effects & No & No & Yes & Yes & No \\
\hline$N$ & 11715 & 10672 & 8973 & 3686 & 8320 \\
\hline \multicolumn{6}{|c|}{$\begin{array}{l}\text { Notes: Robust standard errors, clustered at state-level, are in parentheses. }{ }^{*} p<0.10,{ }^{* *} p<0.05,{ }^{* * *} p<0.01 . \text { This table } \\
\text { uses REDS data. Due to smaller number of observations in REDS } 2006 \text { compared to NFHS, we combine the two } \\
\text { ultrasound periods into a single "Post" dummy variable that captures the full ultrasound period } 1985-2004 \text {. We contro } \\
\text { for state-specific linear trends in Columns } 1 \text { and } 2 \text { since the relevant control variable (state commission) is not identifiec } \\
\text { with state-year fixed effects. For details on the sample and rest of variables, see notes for Tables } 1 \text { and } 2 \text {. We canno } \\
\text { replicate the final column (6) of Table } 2 \text { as REDS does not provide information on mother's ideal number of children. }\end{array}$} \\
\hline
\end{tabular}


Table A4c: Sex Ratios at Birth for Hindu Landowning Families: Using Alternative dataset REDS 2006

\begin{tabular}{|c|c|c|c|c|c|}
\hline & (1) & (2) & (3) & (4) & (5) \\
\hline & \multicolumn{5}{|c|}{ Child is female } \\
\hline \multirow[t]{2}{*}{ First-born is girl*Reform*post } & $-10.41 * * *$ & $-9.30 * *$ & $-8.61^{*}$ & $-8.81 *$ & $-12.94 * *$ \\
\hline & (3.13) & $(3.70)$ & (4.21) & $(4.24)$ & $(4.56)$ \\
\hline Controls & No & No & Yes & Yes & Yes \\
\hline State fixed effects & No & Yes & Yes & Yes & Yes \\
\hline Child year of birth fixed effects & No & Yes & Yes & Yes & Yes \\
\hline State linear trends & No & No & No & Yes & No \\
\hline State-year of birth fixed effects & No & No & No & No & Yes \\
\hline $\mathrm{N}$ & 10851 & 10851 & 9869 & 9869 & 9869 \\
\hline \multicolumn{6}{|c|}{$\begin{array}{l}\text { Notes: Robust standard errors, clustered at state-level, are in parentheses. }{ }^{*} p<0.10, * * p<0.05, * * * p<0.01 \text {. This table } \\
\text { uses REDS data for families who are subject to Hindu law (Hindus, Sikhs, Jains, and Buddhists) with landowning } \\
\text { patriarchs (the grandparents of the generation we observe here), and is restricted up to second births. Due to smaller } \\
\text { number of observations in REDS } 2006 \text { compared to NFHS, we combine the two ultrasound periods into a single "Post" } \\
\text { dummy variable that captures the full ultrasound period } 1985-2004 \text {. Control variables include household wealth, } \\
\text { parental education, religion dummies, high-caste dummy and age group categories of mother. For details on the rest of } \\
\text { variables, see notes for Table } 1 .\end{array}$} \\
\hline
\end{tabular}

Table A5: Sex Ratios at Birth: Excluding northern states

\begin{tabular}{|c|c|c|c|c|c|}
\hline & (1) & (2) & (3) & (4) & (5) \\
\hline & \multicolumn{5}{|c|}{ Child is female } \\
\hline \multirow[t]{2}{*}{ First-born is girl*Reform*p2 } & $-5.17 * * *$ & $-5.09 * * *$ & $-5.06 * * *$ & $-5.09 * * *$ & $-5.71 * * *$ \\
\hline & $(1.58)$ & $(1.57)$ & (1.58) & (1.62) & $(1.84)$ \\
\hline \multirow[t]{2}{*}{ First-born is girl*Reform*p3 } & $-5.70 * * *$ & $-5.46 * * *$ & $-5.46 * * *$ & $-5.39 * * *$ & $-5.48 * *$ \\
\hline & $(1.54)$ & $(1.50)$ & (1.49) & $(1.48)$ & $(2.06)$ \\
\hline Controls & No & Yes & Yes & Yes & No \\
\hline State fixed effects & Yes & Yes & Yes & Yes & No \\
\hline Cohort fixed effects & Yes & Yes & Yes & Yes & Yes \\
\hline State linear trends & No & No & Yes & No & Yes \\
\hline State-year fixed effects & No & No & No & Yes & No \\
\hline Mother fixed effects & No & No & No & No & Yes \\
\hline $\mathrm{N}$ & 210620 & 207761 & 207761 & 207761 & 210620 \\
\hline \multicolumn{6}{|c|}{$\begin{array}{l}\text { Notes: Robust standard errors, clustered at state-level, are in parentheses. }{ }^{*} p<0.10,{ }^{*} p<0.05,{ }^{* * *} p<0.01 . \text { This } \\
\text { table uses NFHS data, is restricted to up to second births, with birth cohorts from } 1972 \text { to } 2004 \text {. The dependent } \\
\text { variable is a dummy that equals } 1 \text { if birth is female and zero otherwise, multiplied by } 100 \text {. "First-born is girl" is a } \\
\text { dummy that equals } 1 \text { if the first-born child in the family is a girl, and zero otherwise. "Reform" is a dummy that equals } \\
1 \text { if the child is born after the reform in the reforming state and zero if they are born before the reform or in a non- } \\
\text { reforming state. The reforming states are Kerala (1976), Andhra Pradesh (1986), Tamil Nadu (1989), Karnataka (1994) } \\
\text { and Maharashtra (1994). "p2" and "p3" are dummy variables that capture the early (1985-94) and later (1995-2004) } \\
\text { phases of ultrasound availability. Control variables include household wealth, parental education, urban dummy, } \\
\text { religion dummies, high-caste dummy and age group categories of mother. With mother fixed effects, most of these } \\
\text { controls are not identified since they do not vary within household, hence are not included. All necessary level and } \\
\text { double-interaction terms are included but not reported. Northern states are Haryana, Himachal Pradesh, New Delhi, } \\
\text { Punjab, Rajasthan, UP. }\end{array}$} \\
\hline
\end{tabular}

Table A6: Sex Ratios at Birth: Excluding eastern states

\begin{tabular}{llllll}
\hline & $(1)$ & $(2)$ & $(3)$ & $(4)$ & $(5)$ \\
\cline { 2 - 6 } & \multicolumn{5}{c}{ Child is female } \\
\hline First-born is girl*Reform*p2 & $-3.87^{* *}$ & $-3.76^{* *}$ & $-3.73^{* *}$ & $-3.78^{* *}$ & $-5.49^{* *}$ \\
& $(1.67)$ & $(1.66)$ & $(1.66)$ & $(1.69)$ & $(1.92)$
\end{tabular}




\begin{tabular}{|c|c|c|c|c|c|}
\hline First-born is girl*Reform*p3 & $\begin{array}{r}-2.90 \\
(1.76) \\
\end{array}$ & $\begin{array}{r}-2.72 \\
(1.71) \\
\end{array}$ & $\begin{array}{r}-2.69 \\
(1.70)\end{array}$ & $\begin{array}{r}-2.57 \\
(1.66)\end{array}$ & $\begin{array}{r}-4.10 \\
(2.43)\end{array}$ \\
\hline Controls & No & Yes & Yes & Yes & No \\
\hline State fixed effects & Yes & Yes & Yes & Yes & No \\
\hline Cohort fixed effects & Yes & Yes & Yes & Yes & Yes \\
\hline State linear trends & No & No & Yes & No & Yes \\
\hline State-year fixed effects & No & No & No & Yes & No \\
\hline Mother fixed effects & No & No & No & No & Yes \\
\hline $\mathrm{N}$ & 212613 & 210336 & 210336 & 210336 & 212613 \\
\hline \multicolumn{6}{|c|}{$\begin{array}{l}\text { Notes: Robust standard errors, clustered at state-level, are in parentheses. * } p<0.10,{ }^{*} p<0.05, * * * p<0.01 \text {. This } \\
\text { table uses NFHS data, is restricted to up to second births, with birth cohorts from } 1972 \text { to } 2004 \text {. The dependent } \\
\text { variable is a dummy that equals } 1 \text { if birth is female and zero otherwise, multiplied by } 100 \text {. "First-born is girl" is a } \\
\text { dummy that equals } 1 \text { if the first-born child in the family is a girl, and zero otherwise. "Reform" is a dummy that } \\
\text { equals } 1 \text { if the child is born after the reform in the reforming state and zero if they are born before the reform or } \\
\text { in a non-reforming state. The reforming states are Kerala (1976), Andhra Pradesh (1986), Tamil Nadu (1989), } \\
\text { Karnataka (1994) and Maharashtra (1994). "p2" and "p3" are dummy variables that capture the early (1985-94) } \\
\text { and later (1995-2004) phases of ultrasound availability. Control variables include household wealth, parental } \\
\text { education, urban dummy, religion dummies, high-caste dummy and age group categories of mother. With mother } \\
\text { fixed effects, most of these controls are not identified since they do not vary within household, hence are not } \\
\text { included. All necessary level and double-interaction terms are included but not reported. Eastern states are } \\
\text { Assam, Bihar, Arunachal Pradesh, Manipur, Meghalaya, Mizoram, Nagaland, Orissa, Sikkim, West Bengal, Tripura. }\end{array}$} \\
\hline
\end{tabular}

Table A7: Proportion of Female Births: Mother Exposure to Reform

\begin{tabular}{|c|c|c|c|}
\hline & (1) & $(2)$ & (3) \\
\hline & \multicolumn{3}{|c|}{ Girls/total children } \\
\hline \multirow[t]{2}{*}{ Mother exposure } & $-0.01 * * *$ & $-0.01 * * *$ & -0.01 \\
\hline & $(0.00)$ & $(0.00)$ & $(0.01)$ \\
\hline Controls & No & Yes & Yes \\
\hline State fixed effects & Yes & Yes & Yes \\
\hline Mother year of birth fixed effects & Yes & Yes & Yes \\
\hline State linear trends & No & No & Yes \\
\hline $\mathrm{N}$ & 490833 & 484501 & 484501 \\
\hline \multicolumn{4}{|c|}{$\begin{array}{l}\text { Notes: }{ }^{*} \mathrm{p}<0.10,{ }^{* *} \mathrm{p}<0.05,{ }^{* * *} \mathrm{p}<0.01 \text {. Robust standard errors, clustered at state-level, are in } \\
\text { parentheses. This table uses NFHS data and all births. The dependent variable is the total number of girl } \\
\text { born to the mother divided by the total number of children born to her }(\mathrm{G} / \mathrm{G}+\mathrm{B}) \text {. 'Reform' is a dumm } \\
\text { that equals } 1 \text { if the mother is } 14 \text { years or less at the time of reform in the reforming state and zerc } \\
\text { otherwise. Control variables include household wealth, parental education, urban dummy, religior } \\
\text { dummies and high-caste dummy. }\end{array}$} \\
\hline
\end{tabular}


Table A8: Reported Son Preference: Full Specification

\begin{tabular}{|c|c|c|c|c|}
\hline & (1) & $(2)$ & (3) & (4) \\
\hline & \multicolumn{4}{|c|}{ Son Preference } \\
\hline \multirow[t]{2}{*}{ First-born is girl } & $-0.02 * * *$ & $-0.02 * * *$ & $-0.02 * * *$ & $-0.02 * * *$ \\
\hline & $(0.00)$ & $(0.00)$ & $(0.00)$ & $(0.00)$ \\
\hline \multirow[t]{2}{*}{ First-born is girl*p2 } & 0.00 & -0.00 & -0.00 & -0.00 \\
\hline & $(0.00)$ & $(0.00)$ & $(0.00)$ & $(0.00)$ \\
\hline \multirow[t]{2}{*}{ First-born is girl*p3 } & 0.00 & 0.00 & 0.00 & 0.00 \\
\hline & $(0.00)$ & $(0.00)$ & $(0.00)$ & $(0.00)$ \\
\hline \multirow[t]{2}{*}{ Reform } & -0.00 & -0.00 & -0.00 & - \\
\hline & $(0.00)$ & $(0.00)$ & $(0.00)$ & \\
\hline \multirow[t]{2}{*}{ Reform*p2 } & -0.00 & -0.00 & -0.00 & - \\
\hline & $(0.00)$ & $(0.00)$ & $(0.00)$ & \\
\hline \multirow[t]{2}{*}{ Reform*p3 } & $-0.01 * *$ & $-0.01^{*}$ & -0.00 & - \\
\hline & $(0.00)$ & $(0.00)$ & $(0.00)$ & \\
\hline \multirow[t]{2}{*}{ First-born is girl*Reform } & -0.01 & $-0.01 *$ & $-0.01 * *$ & $-0.01 * * *$ \\
\hline & $(0.00)$ & $(0.00)$ & $(0.00)$ & $(0.00)$ \\
\hline \multirow[t]{2}{*}{ First-born is girl*Reform*p2 } & $0.01 * *$ & $0.01^{* *}$ & $0.01 * *$ & $0.01 * * *$ \\
\hline & $(0.00)$ & $(0.00)$ & $(0.00)$ & $(0.00)$ \\
\hline \multirow[t]{2}{*}{ First-born is girl*Reform*p3 } & $0.01^{*}$ & $0.01 *$ & $0.01 * *$ & $0.01 * *$ \\
\hline & $(0.00)$ & $(0.00)$ & $(0.00)$ & $(0.00)$ \\
\hline Controls & No & Yes & Yes & Yes \\
\hline State fixed effects & Yes & Yes & Yes & Yes \\
\hline Mother year of birth fixed effects & Yes & Yes & Yes & Yes \\
\hline State linear trends & No & No & Yes & No \\
\hline State-year of birth fixed effects & No & No & No & Yes \\
\hline $\mathrm{N}$ & 412039 & 406775 & 406775 & 406775 \\
\hline
\end{tabular}


Table A9: Female Infant Mortality: Full Specification

\begin{tabular}{|c|c|c|c|c|c|}
\hline & (1) & (2) & (3) & (4) & (5) \\
\hline & \multicolumn{5}{|c|}{ Child dies before turning 1 year old } \\
\hline \multirow[t]{2}{*}{ First-born is girl } & $-2.63 * * *$ & $-1.76 * * *$ & $-1.78 * * *$ & $-1.85 * * *$ & - \\
\hline & $(0.36)$ & $(0.35)$ & $(0.35)$ & $(0.35)$ & \\
\hline \multirow[t]{2}{*}{ First-born is girl*p2 } & $0.95^{*}$ & 0.77 & 0.79 & 0.82 & 0.82 \\
\hline & $(0.52)$ & $(0.53)$ & $(0.52)$ & $(0.52)$ & $(1.13)$ \\
\hline \multirow[t]{2}{*}{ First-born is girl*p3 } & 0.31 & -0.06 & 0.03 & 0.10 & 0.49 \\
\hline & $(0.42)$ & $(0.45)$ & $(0.42)$ & $(0.42)$ & $(1.23)$ \\
\hline \multirow[t]{2}{*}{ Reform } & $-1.63 * * *$ & $-1.45^{* * *}$ & -0.31 & - & -1.19 \\
\hline & $(0.25)$ & $(0.27)$ & $(0.36)$ & & $(0.89)$ \\
\hline \multirow[t]{2}{*}{ Reform*p2 } & $0.88^{* *}$ & $0.93^{* *}$ & 0.20 & - & 0.14 \\
\hline & $(0.33)$ & $(0.35)$ & $(0.23)$ & & $(0.69)$ \\
\hline \multirow[t]{2}{*}{ Reform*p3 } & $1.43^{* *}$ & $1.72 * *$ & $1.21^{*}$ & - & 0.48 \\
\hline & $(0.67)$ & $(0.68)$ & $(0.68)$ & & $(1.71)$ \\
\hline \multirow[t]{2}{*}{ First-born is girl*Reform } & $2.70 * * *$ & $2.42 * * *$ & $2.41 * * *$ & $2.37^{* * *}$ & $4.85 * * *$ \\
\hline & $(0.35)$ & $(0.33)$ & $(0.33)$ & $(0.35)$ & $(0.84)$ \\
\hline \multirow[t]{2}{*}{ First-born is girl*Reform*p2 } & $-1.59 * * *$ & $-1.44^{* *}$ & $-1.43 * *$ & $-1.37 * *$ & $-3.47 * * *$ \\
\hline & $(0.51)$ & $(0.58)$ & $(0.57)$ & $(0.57)$ & $(1.01)$ \\
\hline \multirow[t]{2}{*}{ First-born is girl*Reform*p3 } & $-1.24 * *$ & $-1.15^{* *}$ & $-1.18 * *$ & $-1.19 * *$ & $-3.61 * *$ \\
\hline & $(0.57)$ & $(0.54)$ & $(0.52)$ & $(0.52)$ & $(1.68)$ \\
\hline \multirow[t]{2}{*}{ First-born is girl*Reform*p2*female } & $3.17^{* * *}$ & $3.50 * * *$ & $3.47^{* * *}$ & $3.39 * * *$ & $6.31 * * *$ \\
\hline & $(0.83)$ & $(0.84)$ & $(0.83)$ & $(0.83)$ & $(2.20)$ \\
\hline \multirow[t]{2}{*}{ First-born is girl*Reform*p3*female } & $2.29 * * *$ & $2.57 * * *$ & $2.59 * * *$ & $2.55^{* * *}$ & $6.31 * * *$ \\
\hline & $(0.74)$ & $(0.69)$ & $(0.68)$ & $(0.69)$ & $(2.15)$ \\
\hline \multirow[t]{2}{*}{ Reform*female } & $0.43^{* *}$ & $0.43^{* *}$ & $0.42 * *$ & $0.40^{*}$ & $1.13^{* *}$ \\
\hline & $(0.20)$ & $(0.20)$ & $(0.20)$ & $(0.19)$ & $(0.49)$ \\
\hline \multirow[t]{2}{*}{ First-born is girl*female } & $2.70 * * *$ & $2.60 * * *$ & $2.61 * * *$ & $2.62 * * *$ & $4.68 * * *$ \\
\hline & $(0.51)$ & $(0.51)$ & $(0.51)$ & $(0.52)$ & $(1.13)$ \\
\hline \multirow[t]{2}{*}{ First-born is girl*p2*female } & $-1.78 * *$ & $-1.73^{* *}$ & $-1.73 * *$ & $-1.70 * *$ & -1.14 \\
\hline & $(0.68)$ & $(0.71)$ & $(0.71)$ & $(0.71)$ & $(1.53)$ \\
\hline \multirow[t]{2}{*}{ First-born is girl*p3*female } & $-0.84^{*}$ & $-0.84^{*}$ & $-0.88 * *$ & $-0.87 * *$ & -1.06 \\
\hline & $(0.43)$ & $(0.44)$ & $(0.42)$ & $(0.42)$ & $(1.24)$ \\
\hline \multirow[t]{2}{*}{ First-born is girl*Reform*female } & $-3.03 * * *$ & $-3.17 * * *$ & $-3.15 * * *$ & $-3.10 * * *$ & $-6.47 * * *$ \\
\hline & $(0.53)$ & $(0.54)$ & $(0.53)$ & $(0.52)$ & $(0.95)$ \\
\hline \multirow[t]{2}{*}{ Reform*p2*female } & -0.24 & -0.31 & -0.30 & -0.30 & -0.08 \\
\hline & $(0.33)$ & $(0.34)$ & $(0.34)$ & $(0.34)$ & $(0.84)$ \\
\hline \multirow[t]{2}{*}{ Reform*p3*female } & 0.19 & 0.17 & 0.18 & 0.16 & -0.30 \\
\hline & $(0.49)$ & $(0.47)$ & $(0.47)$ & $(0.46)$ & $(1.36)$ \\
\hline \multirow[t]{2}{*}{ p2*female } & $0.62 * * *$ & $0.60 * * *$ & $0.60 * * *$ & $0.59 * * *$ & 0.26 \\
\hline & $(0.20)$ & $(0.20)$ & $(0.20)$ & $(0.20)$ & $(0.63)$ \\
\hline \multirow[t]{2}{*}{ p3*female } & $0.47^{*}$ & 0.40 & 0.40 & 0.41 & 0.22 \\
\hline & $(0.25)$ & $(0.26)$ & $(0.25)$ & $(0.26)$ & $(0.70)$ \\
\hline \multirow[t]{2}{*}{ female } & $-1.90 * * *$ & $-1.85 * * *$ & $-1.85 * * *$ & $-1.84 * * *$ & $-3.91 * * *$ \\
\hline & $(0.21)$ & $(0.21)$ & $(0.20)$ & $(0.20)$ & $(0.70)$ \\
\hline Controls & No & Yes & Yes & Yes & Yes \\
\hline State fixed effects & Yes & Yes & Yes & Yes & No \\
\hline
\end{tabular}




\begin{tabular}{lccccc} 
Child year of birth fixed effects & Yes & Yes & Yes & Yes & Yes \\
State linear trends & No & No & Yes & No & Yes \\
State-year of birth fixed effects & No & No & No & Yes & No \\
Mother fixed effects & No & No & No & No & Yes \\
\hline $\mathrm{N}$ & 305741 & 301831 & 301831 & 301831 & 301831 \\
\hline
\end{tabular}

Notes: Robust standard errors, clustered at state-level, are in parentheses. ${ }^{*} p<0.10,{ }^{* *} p<0.05,{ }^{* * *} p<0.01$. This table uses NFHS data, is restricted to up to second births, with birth cohorts from 1972 to 2004 . The dependent variable captures whether the child died on or before their first birthday, multiplied by 100. "female" is a dummy that captures if the index child is a girl. For details on sample and variables, see notes for Table 1. In column 4, the level effect of the reform as well as its interactions with the p2 (early ultrasound) and p3 (late ultrasound) dummies are no longer identified after the inclusion of state-year of birth fixed effects. In column 5, girl1 is no longer identified after the inclusion of mother fixed effects.

\section{Table A10: Fertility: Full Specification}

\begin{tabular}{|c|c|c|c|c|c|}
\hline & (1) & (2) & (3) & (4) & $(5)$ \\
\hline & \multicolumn{5}{|c|}{ Has younger sibling } \\
\hline \multirow[t]{2}{*}{ First-born is girl } & $-2.08 * * *$ & -0.02 & 0.00 & -0.02 & - \\
\hline & $(0.57)$ & $(0.49)$ & $(0.49)$ & $(0.49)$ & \\
\hline \multirow[t]{2}{*}{ First-born is girl*p2 } & $-2.28 * * *$ & $-2.23 * * *$ & $-2.27 * * *$ & $-2.25 * * *$ & $-3.24 * * *$ \\
\hline & $(0.54)$ & $(0.55)$ & $(0.55)$ & $(0.54)$ & $(0.98)$ \\
\hline \multirow[t]{2}{*}{ First-born is girl*p3 } & $-2.93 * * *$ & $-2.86 * * *$ & $-2.91 * * *$ & $-2.88 * * *$ & $-10.81 * * *$ \\
\hline & $(0.56)$ & $(0.56)$ & $(0.56)$ & $(0.55)$ & $(1.55)$ \\
\hline \multirow[t]{2}{*}{ Reform } & $7.89 * * *$ & $5.70 * * *$ & $5.47 * * *$ & - & $9.19 * * *$ \\
\hline & $(0.75)$ & (0.69) & (1.09) & & $(1.33)$ \\
\hline \multirow[t]{2}{*}{ Reform*p2 } & $-7.66 * * *$ & $-5.75 * * *$ & $-5.38 * * *$ & - & $-6.95 * * *$ \\
\hline & $(0.82)$ & $(0.69)$ & $(0.77)$ & & $(1.76)$ \\
\hline \multirow[t]{2}{*}{ Reform*p3 } & $-5.95 * * *$ & $-3.56 * *$ & -2.88 & - & $-8.11 * *$ \\
\hline & $(1.51)$ & $(1.55)$ & $(2.00)$ & & $(3.00)$ \\
\hline \multirow[t]{2}{*}{ First-born is girl*Reform } & $-16.11 * * *$ & $-15.51 * * *$ & $-15.57 * * *$ & $-15.34 * * *$ & $-14.34 * * *$ \\
\hline & $(0.57)$ & $(0.62)$ & $(0.63)$ & $(0.62)$ & $(1.08)$ \\
\hline \multirow[t]{2}{*}{ First-born is girl*Reform*p2 } & 3.30 & 2.52 & 2.59 & 2.45 & 3.28 \\
\hline & $(3.90)$ & (3.79) & (3.78) & $(3.84)$ & $(4.68)$ \\
\hline \multirow[t]{2}{*}{ First-born is girl*Reform*p3 } & $8.56^{* * *}$ & $8.10 * * *$ & $8.19 * * *$ & $7.90 * * *$ & $12.33 * * *$ \\
\hline & $(1.96)$ & $(2.00)$ & (1.98) & $(2.07)$ & $(2.94)$ \\
\hline Controls & No & Yes & Yes & Yes & No \\
\hline State fixed effects & Yes & Yes & Yes & Yes & Yes \\
\hline Child year of birth fixed effects & Yes & Yes & Yes & Yes & Yes \\
\hline State linear trends & No & No & Yes & No & Yes \\
\hline State-year of birth fixed effects & No & No & No & Yes & No \\
\hline Mother fixed effects & No & No & No & No & Yes \\
\hline $\mathrm{N}$ & 305741 & 301831 & 301831 & 301831 & 305741 \\
\hline
\end{tabular}

Notes: Robust standard errors, clustered at state-level, are in parentheses. ${ }^{*} p<0.10,{ }^{* *} p<0.05,{ }^{* * *} p<0.01$. This table uses NFHS data, is restricted to up to second births, with birth cohorts from 1972 to 2004 . The dependent variable captures whether the child has younger brothers or sisters, multiplied by 100 . For details on sample and variables, see notes for Table 1 . In column 4 , the level effect of the reform as well as its interactions with the p2 (early ultrasound) and p3 (late ultrasound) dummies are no longer identified after the inclusion of state-year of birth fixed effects. In column 5, girl1 is no longer identified after the inclusion of mother fixed effects 
Table A11: Patrilocality: Alternative distance measure

\begin{tabular}{lccc} 
& $(1)$ & $(2)$ & $(3)$ \\
\cline { 2 - 4 } & \multicolumn{4}{c}{ Marital \& Natal Homes <20km Apart } \\
\hline Exposure to Reform & 0.03 & $0.03^{*}$ & -0.00 \\
& $(0.02)$ & $(0.02)$ & $(0.02)$ \\
\hline Controls & No & Yes & Yes \\
State fixed effects & Yes & Yes & Yes \\
Year of birth fixed effects & Yes & Yes & Yes \\
State linear trends & No & No & Yes \\
\hline N & 43035 & 37283 & 37283 \\
\hline Notes: This table uses REDS data. See further notes in Table 7. & &
\end{tabular}

Table A12: Means of Outcome Variables

\begin{tabular}{llc}
\hline outcome & variable used to measure & mean \\
\hline NFHS & probability of female birth (\%) & 48.07 \\
sex ratio & ideal no. of boys/ideal no. of children & 0.57 \\
son preference & child dies before first birthday (\%) & 7.3 \\
infant girl mortality & child dies before first birthday (\%) & 7.7 \\
infant boy mortality & child has younger siblings (\%) & 73.2 \\
fertility (up to birth order 2) & & \\
& & 0.24 \\
REDS & Probability that adult married son co-resides with parent & 0.19 \\
co-residence & probability that daughter's marital and natal homes<10km apart \\
marriage distance & &
\end{tabular}

Table A13: Pre-Reform Balance Test in Reforming and Non-reforming States, 1970-75

\begin{tabular}{|c|c|c|c|}
\hline & Non-Reform & Reform & Difference \\
\hline & (1) & $(2)$ & (1)-(2) \\
\hline \multirow[t]{2}{*}{ Child is female } & 47.82 & 49.91 & -2.09 \\
\hline & $(49.96)$ & $(50.01)$ & {$[1.73]$} \\
\hline \multirow[t]{2}{*}{ Son preference [ideal $b /(b+g)]$} & 0.60 & 0.56 & $0.04 * *$ \\
\hline & $(0.14)$ & $(0.14)$ & {$[0.01]$} \\
\hline \multirow[t]{2}{*}{ First born in family is a boy } & 0.15 & 0.14 & 0.01 \\
\hline & $(0.35)$ & $(0.34)$ & {$[0.01]$} \\
\hline \multirow[t]{2}{*}{ Mother has secondary or higher education } & 0.02 & 0.03 & -0.01 \\
\hline & $(0.15)$ & $(0.16)$ & {$[0.01]$} \\
\hline \multirow[t]{2}{*}{ Father has secondary or higher education } & 0.11 & 0.09 & 0.02 \\
\hline & $(0.32)$ & $(0.29)$ & {$[0.02]$} \\
\hline \multirow[t]{2}{*}{ Urban } & 0.30 & 0.32 & -0.02 \\
\hline & $(0.46)$ & $(0.47)$ & {$[0.04]$} \\
\hline \multirow[t]{2}{*}{ Hindu } & 0.75 & 0.78 & -0.03 \\
\hline & $(0.43)$ & $(0.41)$ & {$[0.07]$} \\
\hline \multirow[t]{2}{*}{ Richest wealth quintile } & 0.22 & 0.24 & -0.02 \\
\hline & $(0.42)$ & $(0.43)$ & {$[0.04]$} \\
\hline High caste & 0.56 & 0.63 & -0.07 \\
\hline
\end{tabular}




\begin{tabular}{lccc} 
& $(0.50)$ & $(0.48)$ & {$[0.05]$} \\
\hline $\mathrm{N}$ & 9381 & 2839 & 12220 \\
\hline $\begin{array}{l}\text { Notes: }{ }^{*} p<0.10,{ }^{* *} p<0.05,{ }^{* * *} p<0.01 . \text { Standard deviations are in parentheses. Standard errors, clustered at the state level, are in } \\
\text { brackets. This table uses NFHS data. }\end{array}$
\end{tabular}

Table A14: Test of balance in various time periods, by firstborn sex

\begin{tabular}{|c|c|c|c|c|c|c|c|}
\hline & \multicolumn{2}{|c|}{$1973-1984$} & \multicolumn{2}{|c|}{$1985-1994$} & \multicolumn{2}{|c|}{$1995-2005$} & \multirow{2}{*}{$\frac{\text { All years }}{\text { FB-FG }}$} \\
\hline & FB & FG & FB & $\mathrm{FG}$ & FB & FG & \\
\hline & (1) & (2) & (3) & (4) & (5) & (6) & (7) \\
\hline Rural & 0.68 & 0.68 & 0.64 & 0.65 & 0.59 & 0.58 & -0.0004 \\
\hline Hindu & 0.78 & 0.78 & 0.76 & 0.76 & 0.73 & 0.74 & -0.0009 \\
\hline Muslim & 0.11 & 0.11 & 0.12 & 0.12 & 0.13 & 0.13 & -0.0001 \\
\hline SC & 0.14 & 0.14 & 0.15 & 0.16 & 0.16 & 0.17 & $-0.0030^{*}$ \\
\hline ST & 0.12 & 0.13 & 0.13 & 0.13 & 0.14 & 0.13 & -0.0002 \\
\hline \multicolumn{8}{|l|}{ Mother's Education } \\
\hline No education & 0.59 & 0.58 & 0.48 & 0.49 & 0.32 & 0.32 & 0.0020 \\
\hline Incomplete secondary & 0.35 & 0.36 & 0.40 & 0.40 & 0.48 & 0.48 & -0.0020 \\
\hline Secondary or higher & 0.06 & 0.07 & 0.11 & 0.11 & 0.20 & 0.20 & 0.0000 \\
\hline \multicolumn{8}{|l|}{ Father's Education } \\
\hline No education & 0.32 & 0.31 & 0.26 & 0.27 & 0.18 & 0.18 & -0.0020 \\
\hline Incomplete secondary & 0.50 & 0.50 & 0.52 & 0.52 & 0.58 & 0.58 & -0.0005 \\
\hline Secondary or higher & 0.18 & 0.19 & 0.22 & 0.21 & 0.24 & 0.24 & 0.0010 \\
\hline \multicolumn{8}{|l|}{ Mother's birth cohort } \\
\hline $1942-1960$ & 0.52 & 0.52 & 0.04 & 0.04 & 0.00 & 0.00 & 0.0020 \\
\hline 1961-1970 & 0.48 & 0.48 & 0.56 & 0.56 & 0.07 & 0.06 & 0.0010 \\
\hline 1971-1987 & 0.00 & 0.00 & 0.41 & 0.40 & 0.93 & 0.93 & -0.0030 \\
\hline \multicolumn{8}{|l|}{ Mother's age at birth } \\
\hline $12-15$ & 0.14 & 0.13 & 0.11 & 0.11 & 0.05 & 0.06 & 0.0010 \\
\hline $16-18$ & 0.35 & 0.35 & 0.32 & 0.32 & 0.26 & 0.26 & 0.0020 \\
\hline $19-24$ & 0.44 & 0.44 & 0.47 & 0.48 & 0.53 & 0.53 & -0.0020 \\
\hline $25-30$ & 0.07 & 0.07 & 0.09 & 0.09 & 0.14 & 0.13 & -0.0010 \\
\hline $31-49$ & 0.01 & 0.01 & 0.01 & 0.01 & 0.02 & 0.02 & 0.0002 \\
\hline \multicolumn{8}{|l|}{ Household wealth } \\
\hline 2nd quintile & 0.15 & 0.14 & 0.16 & 0.17 & 0.16 & 0.16 & 0.0000 \\
\hline 3rd quintile & 0.17 & 0.17 & 0.17 & 0.17 & 0.18 & 0.18 & -0.0010 \\
\hline 4th quintile & 0.21 & 0.21 & 0.23 & 0.22 & 0.23 & 0.23 & 0.0010 \\
\hline Richest quintile & 0.23 & 0.23 & 0.24 & 0.23 & 0.27 & 0.27 & 0.0030 \\
\hline N (1st births) & 26,064 & 23,905 & 41,430 & 38712 & 22108 & 21,074 & 173,293 \\
\hline
\end{tabular}




\section{Online Appendix B: Discussion on effect size for sex ratios}

The estimated effect sizes on the sex ratio are large, which may appear to stand at odds with the fact that son preference has, historically, been lower in the South. However, ultrasound usage in the South has overtaken usage in the North, as is shown below in Tables B3 and B4 respectively.

Some of the reforming states (Maharashtra and Andhra Pradesh) are among the topranking states practicing sex-selective abortion in our representative NFHS data. For children of birth order two in families with a first born girl after the arrival of ultrasound in 1985 (the treated group in our analysis), we calculated the number of sex-selective abortions for each state using this formula, following Sen (1990):

$$
\text { No. of abortions }=[\text { no. of boys* }(\text { natural sex ratio })]-[\text { no. of girls }]
$$

where the natural sex ratio is 1.05 females per male, according to the World Health Organization. For this group, Maharashtra ranks 4th out of the 16 major states both for the number of abortions and for abortions as a proportion of total female population for that birth order (see Table B1 below). This is also consistent with evidence from census data which shows Maharashtra ranks $6^{\text {th }}$ out of 16 states in the male-bias of the sex ratios in 1991 (Census of India, 1991). Andhra Pradesh, ranks $6^{\text {th }}$ in number of abortions (and $7^{\text {th }}$ in proportions), see Table B1 below.

Table B1: State-wise Sex-selective Abortions in NFHS

Table B1: State-wise Sex-selective Abortions in NFHS
\begin{tabular}{|l|c|c|c|c|c|c|}
\hline States & boys & girls & $\begin{array}{c}\text { no. of } \\
\text { abortions }\end{array}$ & rank & $\begin{array}{c}\text { proportion } \\
\text { abortions }\end{array}$ & rank \\
\hline Uttar Pradesh & 3,262 & 2,793 & 632 & 1 & 0.23 & 3 \\
\hline Punjab & 1,043 & 735 & 360 & 2 & 0.49 & 1 \\
\hline Madhya Pradesh & 2,154 & 1,923 & 339 & 3 & 0.18 & 8 \\
\hline Maharashtra & 1,778 & 1,536 & 331 & 4 & 0.22 & 4 \\
\hline Rajasthan & 1,503 & 1,290 & 288 & 5 & 0.22 & 4 \\
\hline Andhra Pradesh & 1,310 & 1,151 & 225 & 6 & 0.20 & 7 \\
\hline Gujarat & 1,059 & 922 & 190 & 7 & 0.21 & 6 \\
\hline Orissa & 1,218 & 1,089 & 190 & 8 & 0.17 & 9 \\
\hline Haryana & 876 & 735 & 185 & 9 & 0.25 & 2 \\
\hline Assam & 919 & 846 & 119 & 10 & 0.14 & 10 \\
\hline West Bengal & 1,211 & 1,161 & 111 & 11 & 0.10 & 12 \\
\hline Karnataka & 1,264 & 1,219 & 108 & 12 & 0.09 & 13 \\
\hline Tamil Nadu & 1,211 & 1,168 & 104 & 13 & 0.09 & 13 \\
\hline Himachal Pradesh & 827 & 782 & 86 & 14 & 0.11 & 11 \\
\hline
\end{tabular}




\begin{tabular}{|l|c|c|c|c|c|c|} 
Kerala & 800 & 817 & 23 & 15 & 0.03 & 15 \\
\hline India & 26,509 & 23,647 & 4187 & - & 0.18 & - \\
\hline
\end{tabular}

Source: Our calculations using NFHS 1992, 1998 and 2005. The sample here is children of birth order two in families with a first born girl after the arrival of ultrasound in 1985. Abortions are calculated using the above formula.

The total proportion of sex-selective abortions for birth order two children conditional on a first born girl after the introduction of ultrasound in 1985 is presented in Table B2 below. For the reforming states the average is about $13 \%$, which is larger than the estimated coefficient of about $4 \%$.

Table B2: Sex-selective Abortions in NFHS post ultrasound (after 1985) for birth order 2, firstborn girl families: Reforming versus Non-reforming States

\begin{tabular}{|l|c|c|c|c|}
\hline & Boys & girls & $\begin{array}{c}\text { sex-selective } \\
\text { abortions }\end{array}$ & $\begin{array}{c}\text { missing girls as \% of } \\
\text { live girls }\end{array}$ \\
\hline Reforming states & 6363 & 5891 & 790 & 0.13 \\
\hline Non-reforming states & 20146 & 17756 & 3397 & 0.19 \\
\hline All states & 26509 & 23647 & 4187 & 0.18 \\
\hline
\end{tabular}

Source: Our calculations using NFHS 1992, 1998 and 2005.

Table B3: Reported Ultrasound Use

\begin{tabular}{|l|c|c|c|}
\hline & NFHS 1998 & NFHS 2005 & Average \\
\hline Reforming states & 0.08 & 0.24 & 0.16 \\
\hline Non-reforming states & 0.03 & 0.12 & 0.07 \\
\hline
\end{tabular}

Another notable fact that we have not seen explicit in previous work and thus is worth highlighting is that the penetration of ultrasound access in rural areas was significantly greater in the reforming than in the non-reforming states, at $10 \%$ vs $4 \%$ (see Table B4 below). In fact it was not far off the 14\% rate of reported ultrasound use in urban areas of non-reforming states. This is relevant since households with ancestral land that were most effectively exposed to the inheritance reform were disproportionately resident in rural areas.

Table B4: Reported Ultrasound usage: Reform vs non-reform, land vs non-land

\begin{tabular}{|l|c|c|c|c|}
\hline & total & rural & urban & diff \\
\hline Reforming & 0.16 & 0.10 & 0.23 & $0.13^{* * *}$ \\
\hline Non-reforming & 0.07 & 0.04 & 0.14 & $0.10^{* * *}$ \\
\hline All states & 0.09 & 0.05 & 0.16 & $0.11^{* * *}$ \\
\hline
\end{tabular}

Source: Our calculations using NFHS 1998 and 2005. 
Online Appendix C: Heterogeneous Effects of the Inheritance Reform by Religion and Land Ownership

The reason we do not present in the paper a specification that leverages the greater exposure to Hindu land-owning households to the reform is that our main specification, Equation 1 in the paper, involves an interaction between inheritance reform (which changed incentives) and indicators for the availability of ultrasound scanners (which lower costs). There is no reason to believe that when ultrasound first became available in the country, it was similarly accessible by Hindu vs Muslim or land-owning vs landless households.

For instance, Muslims are significantly more likely to live in urban areas (see Table C1 below) and Table B4 presented above confirms that ultrasound usage was significantly greater in urban than in rural areas. Thus Muslims had greater and earlier access to ultrasound than Hindus but were less affected by the inheritance reform. Similarly landless households are more present in urban areas than rural (80\% vs 35\%) but land-owning households were more exposed to the reform. For these reasons, we did not have a prior that in a specification including the interaction with post-ultrasound, we will see that Hindu and land-owning households commit more sex selection. Using this interaction would not be clean as the different "treatments" can pull in different directions.

Table C1: Percentage of Muslim population

\begin{tabular}{|l|c|c|c|c|}
\hline & Total & Rural & Urban & Difference \\
\hline Reforming states & 0.14 & 0.09 & 0.20 & $0.11^{* * *}$ \\
\hline All states & 0.12 & 0.10 & 0.17 & $0.07^{* * *}$ \\
\hline
\end{tabular}

Source: Our calculations using NFHS 1992, 1998 and 2005. 


\section{Online Appendix D: Challenges of measuring ancestral land in NFHS and REDS}

NFHS: Land ownership is measured only at the time of survey. In addition, land ownership data in NFHS is highly aggregated: the question asked is whether or not the household owns land. It does not distinguish between ancestral and non-ancestral land, but this distinction matters because the reform only applies to inheritance in the former type of land. A family classified as "landowning" may not own any ancestral land (and hence would not be affected by the reform) while a family classified as "non-landowning" may be affected by the reform if the father (and hence his sons and daughters) in the family are eligible to inherit ancestral land but haven't done so yet at the time of survey because their ancestor(s) is still alive. Both a) and b) would introduce measurement error

REDS: Despite the very detailed, important measures of land ownership and inheritance that the REDS 2006 round provides, the combination of conceptual and practical measurement challenges make land inheritance a particularly difficult variable to analyse. The inheritance reform refers to ancestral land. According to Hindu Law, property inherited from one's father, grandfather, or grandfather's father constitutes ancestral property (Mulla's Principles of Hindu Law, $15^{\text {th }}$ Edition, pg. 289). So one potential measure is based on the greatest generational distance we are able to study using the REDS 2006 round: land ownership by the grandfather of the generation we study here (the household head's children). We are able to identify land ownership acreage whenever household heads report the amount of land (irrigated and unirrigated) owned by their parents (which, given traditional practice, is likely to be held entirely by the male patriarch).

This is not a perfectly accurate measure of the stock of land inheritance available to a given child for two reasons. First: some amount of the grandfather's land, potentially including the entirety of the property, may have already been partitioned amongst the family members who held it in common (known as coparceners) prior to a given child's birth. Any partitioned property is subsequently considered privately held, and thus it is no longer deemed ancestral land available for inheritance.

A second challenge to using this measure is practical: 35 percent of observations $(4,100$ of 11,715 second birth order children in birth cohorts from 1972-2004) do not have data on the head's parents' land ownership. Out of the remaining observations, none record zero land ownership by the head's parents. As a result, it is difficult to accurately identify which missing observations indicate zero land ownership versus unwillingness to report land ownership. 
An alternative measure is based on the head's reported acreage of inherited land. This is likely to be a more accurate measure of the stock of land inheritance available for a given child to inherit, but is also incomplete, as parents may decide to "gift" some or all of their share of inheritance to one or more of their (often male) children, to avoid the legal obligation to transfer ancestral land to other (often female) children (Roy 2015).

There is also a practical challenge here: 49 percent of observations $(5,724$ of 11,715$)$ have no data on father's acreage of land inheritance. In this case, 1.4 percent of observations report zero acres of inherited land by the father $(167$ of 11,715$)$, which makes it even more difficult to parse what amount of the missing observations indicate zero land inheritance versus unwillingness to report.

A third option is to measure the acreage of land inheritance by the spouse of the household head (the mother of the children studied here). Here, problems of nonreporting are most severe: we have data on only 2.8 percent of cases $(331$ of 11,715), with none of these observations reporting zero land inheritance by the given woman. 